\title{
Tropical Cyclone Track and Structure Sensitivity to Initialization in Idealized Simulations: A Preliminary Study
}

\author{
Yang Cao, Robert G. Fovell *, and Kristen L. Corbosiero \\ Department of Atmospheric and Oceanic Sciences, University of California, Los Angeles, California, USA
}

Received 28 February 2011, accepted 12 May 2011

\begin{abstract}
In the absence of environmental steering, tropical cyclone (TC) motion largely reflects "beta drift" owing to differential planetary vorticity advection by the storm's outer circulation. It is known that model physics choices (especially those relating to convection) can significantly alter these outer winds and thus the storm track. Here, semi-idealized simulations are used to explore the influence of the initialization on subsequent vortex evolution and motion. Specifically, TCs bred from a buoyant "bubble" are compared to bogussed vortices having a wide variety of parameterized shapes and sizes matching observations.

As expected, the bogussed storms commencing with the strongest outer winds propagated fastest and, as a result, huge structure-dependent position differences quickly appeared. However, the forward speed variation among the initially bogussed TCs subsequently declined as a progressive homogenization harmonized the initially supplied structural differences. The homogenization likely involved model physics such as microphysics. This result casts doubt on the ability of models to retain and propagate forward information supplied at the initialization by advanced data assimilation techniques or parameterized vortex wind profiles.

Asymmetries in near-core convective heating emerged as an important structural aspect that survived the homogenization tendency. The bubble and bogussed TCs developed markedly different heating patterns, which appear to help explain why the artificially-established storms tended to move about three times faster than their bubble counterparts. The reasons for this are not presently understood fully.
\end{abstract}

Key words: Tropical cyclone, Track, Structure, Ensemble, Bogus

Citation: Cao, Y., R. G. Fovell, and K. L. Corbosiero, 2011: Tropical cyclone track and structure sensitivity to initialization in idealized simulations: A preliminary study. Terr. Atmos. Ocean. Sci., 22, 559-578, doi: 10.3319/TAO.2011.05.12.01(TM)

\section{INTRODUCTION}

Tropical cyclone (TC) track forecast skill has steadily improved (Rogers et al. 2006; Rappaport et al. 2009), thanks to a number of factors, including increased model resolution (e.g., Miyoshi et al. 2010), improved physical parameterizations and ensemble forecasting strategies (e.g., Krishnamurti et al. 1997; Goerss 2000; Srinivas et al. 2007; Fovell and Boucher 2009), and the availability of high-quality satellitederived information, especially over the data-sparse ocean (e.g., Leslie et al. 1998). Enhanced initialization techniques, including data assimilation (e.g., Zou and Xiao 2000; Torn 2010) and TC bogussing (e.g., Kurihara et al. 1990; Lord 1991; Leslie and Holland 1995) have resulted in crucial ad-

\footnotetext{
* Corresponding author

E-mail:rfovell@ucla.edu
}

vances. According to Japan Meteorological Agency (JMA) and Joint Typhoon Warning Center (JTWC) official data, the $24 \mathrm{~h}$ position error for western North Pacific Ocean TCs, however, was still about $110 \mathrm{~km}$ in 2008 (Heming and Goerss 2010), which is large relative to population density variations in many coastal areas (cf. Fovell and Su 2007). Typhoon Morakot (2009) is an excellent illustration of the importance of properly anticipating storm speed and direction, as those factors strongly influenced the resulting topographic impact, moisture advection and rainfall rates. While TC intensity prognoses are by far the more perplexing problem, skillful intensity prediction remains to be of limited usefulness without accurate forecasts of TC motion, which is why track forecast improvement has been such a high priority (Chan 2010). 
TC motion reflects a combination of environmental steering and self-propulsion owing to the "beta effect" (Holland 1983; Chan and Williams 1987), the latter reflecting the differential planetary vorticity advection by the TC's own circulation. This establishes asymmetric gyres that impart a "ventilation flow" across the vortex (Fiorino and Elsberry 1989a), producing northwestward motion in the Northern Hemisphere. This effect emerged in observational studies as a deviation between the TC motion and environmental steering vectors (Chan and Gray 1982; Holland 1984; Carr and Elsberry 1990). Its magnitude is about $1-3 \mathrm{~m} \mathrm{~s}^{-1}$, although sensitivities to translation direction and speed, latitude and intensity have been reported (e.g., Chan and Gray 1982; Holland 1984).

Previous research has demonstrated that while skillful motion prediction is possible without detailed knowledge of the wind structure near the storm center (Holland 1983, 1984; DeMaria 1985, 1987; Chan and Williams 1987), even small variations of several meters per second in the outer wind field have been shown to significantly alter TC direction and speed (Holland 1983; Chan and Williams 1987; Fiorino and Elsberry 1989a, b; Fovell et al. 2009). This is partly due to the fact that the symmetric component of the tangential winds in the $300 \leq \mathrm{R} \leq 800 \mathrm{~km}$ annulus (where $\mathrm{R}=$ radius) determines the beta gyres' magnitude and orientation (Fiorino and Elsberry 1989a; Smith et al. 1990). As a result, anything that influences the extent of a storm can also affect the track. In model simulations, this can include the initial TC size (e.g., Emanuel 1986; Rotunno and Emanuel 1987; Bender et al. 1993; Leroux 2010; Xu and Wang 2010), environmental factors such as relative humidity (Hill and Lackmann 2009b; Wang 2009) and large-scale flow patterns (Liu and Chan 2002; Kimball 2006), and model physical parameterizations including cloud microphysics and cloud-radiative feedback (Fovell and Su 2007; Fovell et al. 2009, 2010). Asymmetries in convective heating, responding at least in part to the beta effect, can also significantly modulate motion (Wu and Wang 2000; Fovell et al. 2010).

The natural variation of the extent of a storm is quite large based upon influences such as the season, basin, environmental pressure, latitude and even time of the day (cf. Xu and Wang 2010). Merrill (1984) showed that the mean radius of the outermost closed isobar of Atlantic hurricanes tended to be smaller than their western North Pacific (WNP) counterparts (being 3.0 vs. $4.4^{\circ}$ latitude). The average radius of maximum wind $\left(\mathrm{R}_{\mathrm{m}}\right)$ in Atlantic and eastern Pacific hurricanes is roughly $45-55 \mathrm{~km}$, with a reasonable range of 10 - $110 \mathrm{~km}$ (Shea and Gray 1973; Hsu and Yan 1998; Kimball and Mulekar 2004; Willoughby and Rahn 2004; Mallen et al. 2005; Vickery and Wadhera 2008). Data are more limited for WNP typhoons as routine reconnaissance flights there were terminated after September 1987, although Weatherford and Gray (1988a, b) reported that the mean WNP TC eye inner radar radius (IRR) for these storms is around $20 \mathrm{~km}$, with a large variation spanning 4 $111 \mathrm{~km}$. Shea and Gray (1973, their Fig. 17) showed that the hurricane $R_{m}$ is typically located about $10-12 \mathrm{~km}$ outward from the IRR. Initial size matters because Cocks and Gray (2002) demonstrated that, in contrast to medium and large typhoons, initially small WNP TCs tended to remain small during their life spans, a result that has been attributed to a positive feedback mechanism (Xu and Wang 2010).

A variety of parametric representations for TC outer wind structure have been proposed that are useful for analyzing wind observations as well as constructing bogus vortices for numerical models (Kepert 2010). The commonly employed modified Rankine (MR) profile is often specified as

$\mathrm{V}(\mathrm{R})=\mathrm{V}_{\mathrm{m}}\left(\frac{\mathrm{R}}{\mathrm{R}_{\mathrm{m}}}\right)^{-\alpha}$

where $\mathrm{V}$ is the tangential wind with maximum value $\mathrm{V}_{\mathrm{m}}$ at $\mathrm{R}=\mathrm{R}_{\mathrm{m}}$, and $\alpha$ is the wind profile decay factor (Depperman 1947; Hughes 1952; Anthes 1982). For a pure Rankine vortex, $\alpha=1$, but smaller values are usually obtained owing to significant frictional loss of angular momentum (Holland 1985), yielding a theoretical or expected value of 0.5 (cf. Riehl 1963; Emanuel 1986). Larger $\alpha$ implies more sharply diminishing winds with increasing radius, and fits to observations have commonly resulted in values in the $1 / 3-2 / 3$ range for both Atlantic and Pacific TCs (e.g., Hughes 1952; Riehl 1954, 1963; Shea and Gray 1973; Shapiro and Willoughby 1982; Merrill 1984; Willoughby 1990; Reasor et al. 2004; Mallen et al. 2005). In particular, Mallen et al.'s (2005) survey of Atlantic and east Pacific hurricanes yielded a mean $\alpha$ of 0.48 for major hurricanes $\left(V_{m}>50 \mathrm{~m} \mathrm{~s}^{-1}\right)$ and progressively smaller values for minimal hurricanes $(\alpha$ $=0.35)$ and prehurricane $(\alpha=0.31)$ storms.

Issues raised concerning the MR function include its tendency to specify overly strong outer winds (e.g., Holland 1980; Goerss and Jeffries 1994), resulting in a poor fit to more than "a short length of observed profiles" (Leslie and Holland 1995). Indeed, Mallen et al. (2005) restricted their MR fits to the interval $1 \leq R / R_{m} \leq 3$, so their comprehensive analyses may not apply to the outer region(s) of particular interest here. Data beyond $150 \mathrm{~km}$, roughly triple the usual $R_{m}$, are typically more sparse (cf. Jorgensen 1984; Willoughby and Rahn 2004).

Two widely used alternatives were presented by Holland (1980) and DeMaria (1987). The Holland (1980), or H80, function represents an improved version of Schloemer's (1954) radial surface pressure profile and is given by

$\mathrm{V}(\mathrm{R})=\mathrm{V}_{\mathrm{m}}\left\{\left(\frac{\mathrm{R}_{\mathrm{m}}}{\mathrm{R}}\right)^{\mathrm{b}} \exp \left[1-\left(\frac{\mathrm{R}_{\mathrm{m}}}{\mathrm{R}}\right)^{\mathrm{b}}\right]\right\}^{0.5}$ 
where $\mathrm{b}$ is an empirically determined parameter that adjusts the profile shape. It is the most extensively used profile (Kepert 2010), although among its limitations is a tendency to decrease winds too quickly for $R / R_{m} \geq \sim 2$ - 3 (Willoughby and Rahn 2004). The DeMaria (1987) formula adopted here is

$\mathrm{V}(\mathrm{R})=\mathrm{V}_{\mathrm{m}}\left(\frac{\mathrm{R}}{\mathrm{R}_{\mathrm{m}}}\right) \exp \left\{\frac{1}{\mathrm{~d}}\left[1-\left(\frac{\mathrm{R}}{\mathrm{R}_{\mathrm{m}}}\right)^{\mathrm{c}}\right]\right\}$

In many applications, parameters $\mathrm{c}$ and $\mathrm{d}$ have been constrained to be equal (Chan and Williams 1987; DeMaria 1987; Fiorino and Elsberry 1989a; Hill and Lackmann $2009 b$ ) or $d$ has been given a fixed value, such as unity (e.g., Smith 1993; Leslie and Holland 1995; Holland et al. 2010; Qiu et al. 2010). Other profiles also exist (e.g., Fujita 1952; Smith et al. 1990; Emanuel 2004; Willoughby et al. 2006), including a recently revised version of H80 (Holland et al. 2010).

This study extends our previous work (Fovell and $\mathrm{Su}$ 2007; Wong 2008; Fovell et al. 2009, 2010) on the influence of model physics, especially cloud microphysics and cloudradiative feedback, on TC structure and track. Again, simulations using an aquaplanet version of the real-data Weather Research and Forecasting (WRF) model are employed, but with a focus on examining how the initial condition influences the subsequent storm evolution. In our past simulations, a TC was established indirectly via a buoyancy perturbation, and this approach is compared to initialization via bogussed vortices crafted with a variety of shapes and sizes. For this preliminary study, artificial vortices based on the MR profile are employed and emphasis is placed on relatively coarse resolutions. Previous research has suggested that track sensitivity to the initial vortex characteristics and model resolution is significant, as vortex structure can be affected (e.g., Elsberry 1995; Leslie and Holland 1995; Miyoshi el al. 2010).

Thus, the present concern is with how strongly the initial conditions influence the subsequent motion and structure of model TCs for fixed model physics. This is a preliminary investigation that may raise more questions than it answers, but represents an initial step towards understanding what might be a key factor behind position forecast errors in operational models employed in TC track forecasting.

\section{MODEL AND EXPERIMENTAL DESIGN}

Our aquaplanet WRF model is based on the Advanced Research WRF (ARW) real-data core, initialized with a modified version of the Jordan (1958) hurricane season sounding (cf. Fovell et al. 2010) and a fixed $\left(29^{\circ} \mathrm{C}\right)$ seasurface temperature. The original intent was to simulate tropical cyclones under simplified and controllable conditions within the same dynamical framework successfully employed with real data for operational and research purposes (e.g., Davis et al. 2008), especially with respect to model physics. For this study, several modifications have been made to this "real-ideal" hybrid originally inspired by Hill and Lackmann (2009a). Still employed are the commonly adopted YSU boundary layer parameterization and RRTM radiation scheme in their default configurations are used here; however, the model is now based on WRF-ARW v. 3.2 and currently utilizes a Lambert projection along with 51 vertical levels beneath the $10 \mathrm{hPa}$ model top.

In our previous studies, TCs were "bred" from a synoptic-scale buoyancy perturbation inserted into an initially calm and otherwise horizontally homogeneous environment with the aid of the Kain-Fritsch (cf. Kain 2004) convective parameterization (CP). With a favorable environment and an aggressive convective scheme, this "bubble" initialization can establish a coherent vortex of tropical storm intensity within about 24 - $30 \mathrm{~h}$. In the past, no cloud microphysical scheme was employed during this spin-up period. It is this vortex and concomitant environmental response that constituted the initial condition for Fovell and Su's (2007) and Fovell et al.'s (2009) examinations of microphysical influence on track and Fovell et al.'s (2010) assessment of the role of cloud-radiative feedback on storm structure and motion.

While it creates a thermodynamically and dynamically balanced circulation, the bubble initialization affords little control over the initial storm's intensity and structure. In this study, we also utilize the brute-force TC bogussing capability that was introduced with WRF version 3. This forges symmetric and genuinely vertically erect vortices with specified core size, coherent vertical structure and outer wind profiles, the latter based on the modified Rankine vortex (1). The benefit of bogussing is that the intensity and structure of the initial TC can be controlled, at some potential loss of realism, at least at the outset.

With regard to the artificial vortices, initial core size (through $\mathrm{R}_{\mathrm{m}}$ ) and outer wind structure (via the MR decay parameter, $\alpha$ ) were varied. Primary emphasis is placed on an experiment utilizing a single, $5220 \mathrm{~km}$ square domain with $36 \mathrm{~km}$ horizontal resolution, but limited comparisons will be made to a much higher resolution experiment utilizing a $9 \mathrm{~km}$ grid enclosing a $3 \mathrm{~km}$ cyclone-tracking nest. The 9 and $3 \mathrm{~km}$ domains were also square with 4500 and $1506 \mathrm{~km}$ sides, respectively. All experiments examined herein utilize the Lin et al. (1983) microphysics scheme, which includes three forms of frozen water (free floating ice crystals, low density snow aggregates and graupel).

The following analysis will focus on the mature TC structure and motion and how it evolved, utilizing timeaveraged, vortex-following composites (cf. Fovell and $\mathrm{Su}$ 2007; Fovell et al. 2009). The $36 \mathrm{~km}$ simulations were integrated for 60 hours, and one focus will be on the last $12 \mathrm{~h}$ or "final period" commencing at $48 \mathrm{~h}$. After $60 \mathrm{~h}$, problems at the lateral boundaries traced to spurious $\mathrm{CP}$ activity 
emerged, so subsequent time periods were ignored. The $3 \mathrm{~km}$ simulations were integrated for $72 \mathrm{~h}$ without lateral boundary issues becoming apparent, so their final period starts at hour 60 . The Kain-Fritsch convective parameterization was active at all times in the coarse resolution runs, while at higher resolution it is used solely with the bubble initialization, and only during the first $24 \mathrm{~h}$. In contrast with previous work, the microphysics scheme was employed from the initial time in all experiments.

\section{RESULTS}

In the $36 \mathrm{~km}$ experiment, artificial vortices with original $R_{m 0}=30,70$ and $110 \mathrm{~km}$ were considered (Tables 1 and 2). It is acknowledged that the first is too small relative to the grid while the last is rather large given the observations cited in the Introduction. Initial Rankine decay parameters of $\alpha_{0}=0.4-0.7$, inclusive, were examined, spanning the range reported in Mallen et al. (2005) for storms of at least hurricane strength. In all cases, the initial maximum intensity was set to be $30 \mathrm{~m} \mathrm{~s}^{-1}$, but in practice the initial maximum wind speed, as well as the initial vortex size, varied somewhat with both $\mathrm{R}_{\mathrm{m} 0}$ and $\alpha_{0}$, which can be detected in the symmetric component of initial $850 \mathrm{hPa}$ wind speed (Fig. 1). The same $\mathrm{V}_{\mathrm{m} 0}$ was employed in the complementary $3 \mathrm{~km}$ experiment that examined $\alpha_{0}=0.5,0.625,0.75$ and 0.9 , with $\mathrm{R}_{\mathrm{m} 0}$ fixed at $40 \mathrm{~km}$ (Tables 2 and 3). In those simulations, the initial vortex was inserted into the $9 \mathrm{~km}$ parent grid, and then interpolated to the higher resolution nest. Maximum initial intensity still varied somewhat, but to a much smaller degree (Fig. 9a, presented later).

\subsection{Model Storm Tracks and Translation Speeds}

In both experiments, the beta drift imparted a generally northwestern motion on the model TCs (Fig. 2; Table 2). Note the final forecasted positions vary enormously, far exceeding those appearing in the microphysics sensitivity experiments of Fovell et al. $(2009,2010)$. A portion of the position discrepancies reflects differences that emerged immediately after integration commenced, thereby representing initial condition sensitivity. These early-appearing deviations are extremely important as their effects are carried forward through the entire forecast. However, emphasis will also be placed on the final $12 \mathrm{~h}$ period, to extract that portion of the initial condition variation that survived to the storms' mature phase.

The artificially established vortices in the $36 \mathrm{~km}$ experiment quickly acquired a variety of translation speeds that, for the faster-moving TCs, peaked around $35 \mathrm{~h}$ before declining substantially during the second half of the simulation (Fig. 3a). The initial motions reflected the magnitude of the originally supplied outer winds, which were greater for larger $R_{\mathrm{m} 0}$ and smaller $\alpha_{0}$ (Fig. 1). At the simulation midpoint, translation speeds varied between 2 and $7 \mathrm{~m} \mathrm{~s}^{-1}$, spanning the range of the most common motion speeds in Corbosiero and Molinari's (2003) study, although it should be borne in mind that these idealized TCs had no truly independent environmental steering. By hour 60 , however, speed variation among the bogussed model storms had become fairly small and more dependent on $\alpha_{0}$ than $\mathrm{R}_{\mathrm{m} 0}$ (Fig. 4). Assuming other factors being equal, smaller $\alpha_{0}$ implies stronger winds at larger radii which, if maintained over the course of the fore-

Table 1. Comparison of initial and final period $R_{m}$ and intensity, and outer-region $\left(R / R_{m} \geq 2\right)$ fit parameters for the symmetric component of the $850 \mathrm{hPa}$ tangential wind for the $36 \mathrm{~km}$ experiment.

\begin{tabular}{|c|c|c|c|c|c|c|c|c|c|c|c|}
\hline \multicolumn{2}{|c|}{ Experiment Name } & \multirow[t]{2}{*}{$\begin{array}{c}\mathbf{R}_{\mathrm{m} 0} \\
(\mathbf{k m})\end{array}$} & \multirow{2}{*}{$\begin{array}{c}\begin{array}{c}\mathbf{R}_{\mathrm{m}} \\
\text { (final }\end{array} \\
\text { period) } \\
(\mathbf{k m})\end{array}$} & \multirow[t]{2}{*}{$\begin{array}{c}\mathrm{V}_{\mathrm{m} 0} \\
\left(\mathrm{~m} \mathrm{~s}^{-1}\right)\end{array}$} & \multirow[t]{2}{*}{$\begin{array}{c}\mathrm{V}_{\mathrm{m}} \\
\text { (final } \\
\text { period) } \\
\left(\mathrm{m} \mathrm{s}^{-1}\right)\end{array}$} & \multicolumn{2}{|c|}{$\begin{array}{c}\text { Initial } \\
\text { Adjusted Rankine Fit }\end{array}$} & \multicolumn{2}{|c|}{$\begin{array}{c}\text { Final period } \\
\text { Adjusted Rankine Fit }\end{array}$} & \multicolumn{2}{|c|}{$\begin{array}{c}\text { Final period } \\
\text { Adjusted } \\
\text { DeMaria87 Fit }\end{array}$} \\
\hline $\mathbf{R}_{\mathrm{m} 0}$ & $\alpha_{0}$ & & & & & $\alpha$ & $\gamma$ & $\alpha$ & $\gamma$ & c & d \\
\hline bubble & --- & --- & 82.9 & 0 & 35.1 & --- & --- & 0.92 & 1.43 & 0.22 & 0.16 \\
\hline \multirow{4}{*}{$30 \mathrm{~km}$} & 0.4 & 72.1 & 86.5 & 18.5 & 42.5 & 0.39 & 1.14 & 0.91 & 1.50 & 0.26 & 0.20 \\
\hline & 0.5 & 61.3 & 82.9 & 17.0 & 40.3 & 0.49 & 1.20 & 0.91 & 1.50 & 0.26 & 0.20 \\
\hline & 0.6 & 54.1 & 75.7 & 15.8 & 36.6 & 0.59 & 1.29 & 0.90 & 1.56 & 0.27 & 0.21 \\
\hline & 0.7 & 50.5 & 75.7 & 14.8 & 31.4 & 0.69 & 1.37 & 0.88 & 1.61 & 0.29 & 0.24 \\
\hline \multirow{4}{*}{$70 \mathrm{~km}$} & 0.4 & 97.3 & 97.3 & 23.5 & 51.6 & 0.39 & 1.10 & 0.92 & 1.40 & 0.23 & 0.16 \\
\hline & 0.5 & 93.7 & 97.3 & 22.7 & 52.0 & 0.49 & 1.13 & 0.94 & 1.37 & 0.21 & 0.15 \\
\hline & 0.6 & 86.5 & 93.7 & 22.0 & 52.4 & 0.59 & 1.18 & 0.94 & 1.35 & 0.20 & 0.14 \\
\hline & 0.7 & 82.9 & 86.5 & 21.4 & 50.6 & 0.69 & 1.23 & 0.93 & 1.41 & 0.22 & 0.15 \\
\hline \multirow{4}{*}{$110 \mathrm{~km}$} & 0.4 & 136.9 & 108.1 & 25.6 & 54.4 & 0.40 & 1.06 & 0.91 & 1.38 & 0.23 & 0.16 \\
\hline & 0.5 & 126.1 & 108.1 & 25.1 & 56.6 & 0.50 & 1.11 & 0.93 & 1.33 & 0.20 & 0.14 \\
\hline & 0.6 & 126.1 & 104.5 & 24.6 & 56.9 & 0.60 & 1.12 & 0.95 & 1.37 & 0.22 & 0.15 \\
\hline & 0.7 & 118.9 & 104.5 & 24.2 & 56.9 & 0.70 & 1.17 & 0.96 & 1.33 & 0.20 & 0.13 \\
\hline
\end{tabular}


cast period, should result in larger differential advection of planetary vorticity and thus enhanced beta drift.

Translation variation among their $3 \mathrm{~km}$ counterparts was also substantial and, in contrast, varied less with time during maturity (Fig. 3b). The reasons for this are unclear, but it should be noted that these higher resolution simulations do not utilize a CP. Final speeds in this experiment were also sensitive to $\alpha_{0}$ (Fig. 4). As a result, the quickly established track divergence - reflecting speed more than directional differences (Table 2) - continued to increase. This illustrates a very substantial sensitivity to the initial condition for the purposes of track forecasting.

With translation speeds of 0.92 and $1.73 \mathrm{~m} \mathrm{~s}^{-1}$ (Table 2) during maturity, the bubble-initialized storms were by far the slowest moving TCs in either experiment (Fig. 3). These speeds are comparable to those in the Fovell et al. (2009, 2010) experiments that incorporated ice microphysics. Note that the bogussed storms translated on average about three times faster than the bubble-bred TC, moving at rates far more comparable to Fovell et al.'s $(2009,2010)$ “warm rain" cases that employed Kessler microphysics. The Kessler
Table 2. Final forward speed and direction for all experiments.

\begin{tabular}{|c|c|c|c|c|}
\hline \multicolumn{3}{|c|}{ Experiment Name } & \multirow{2}{*}{$\begin{array}{c}\text { Final speed } \\
\quad\left(\mathrm{m} \mathrm{s}^{-1}\right)\end{array}$} & \multirow{2}{*}{$\begin{array}{l}\text { Final direction } \\
\text { (degree, } \mathrm{CCW} \\
\text { from } \mathbf{N})\end{array}$} \\
\hline Resolution & $\mathbf{R}_{\mathrm{m} 0}$ & $\alpha_{0}$ & & \\
\hline \multirow{13}{*}{$36 \mathrm{~km}$} & bubble & --- & 1.73 & 63.6 \\
\hline & \multirow{4}{*}{$30 \mathrm{~km}$} & 0.4 & 3.65 & 23.8 \\
\hline & & 0.5 & 3.28 & 27.1 \\
\hline & & 0.6 & 3.14 & 21.2 \\
\hline & & 0.7 & 2.62 & 17.0 \\
\hline & \multirow{4}{*}{$70 \mathrm{~km}$} & 0.4 & 3.99 & 33.1 \\
\hline & & 0.5 & 3.65 & 23.8 \\
\hline & & 0.6 & 3.68 & 37.4 \\
\hline & & 0.7 & 3.13 & 21.1 \\
\hline & \multirow{4}{*}{$110 \mathrm{~km}$} & 0.4 & 3.80 & 28.3 \\
\hline & & 0.5 & 3.81 & 28.7 \\
\hline & & 0.6 & 3.46 & 32.3 \\
\hline & & 0.7 & 3.12 & 36.6 \\
\hline \multirow{5}{*}{$3 \mathrm{~km}$} & bubble & --- & 0.92 & 25.0 \\
\hline & \multirow{4}{*}{$40 \mathrm{~km}$} & 0.5 & 3.70 & 35.1 \\
\hline & & 0.625 & 2.88 & 25.9 \\
\hline & & 0.75 & 2.43 & 25.4 \\
\hline & & 0.9 & 2.30 & 24.6 \\
\hline
\end{tabular}

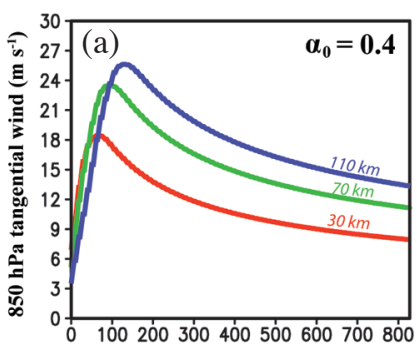
radial distance from eye $(\mathbf{k m})$

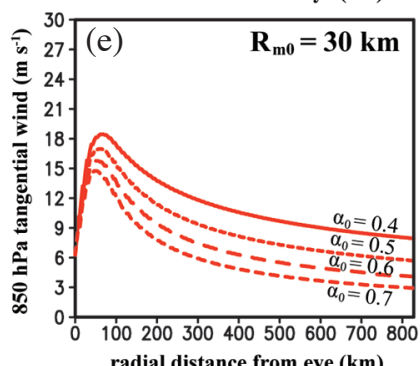

radial distance from eye $(\mathrm{km})$

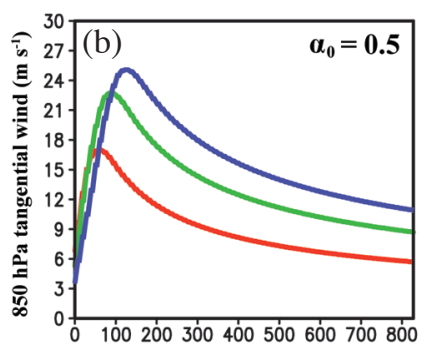

radial distance from eye $(\mathbf{k m})$

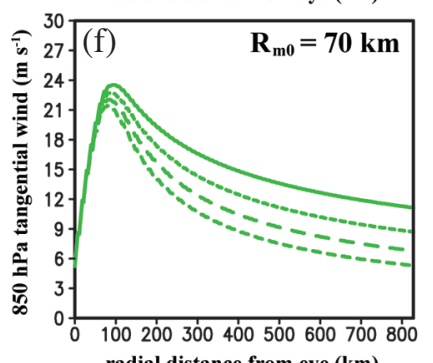

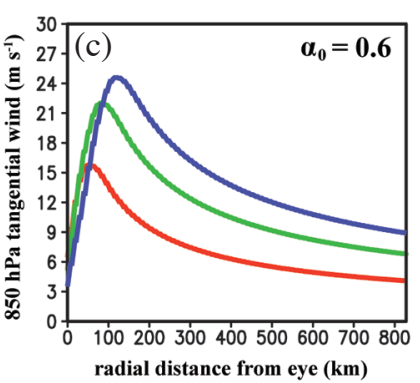

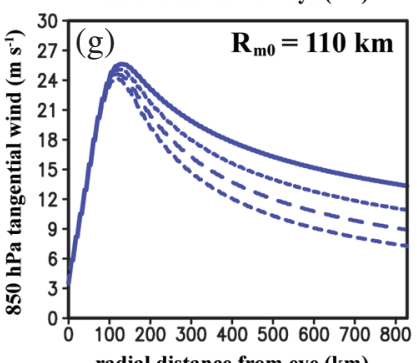

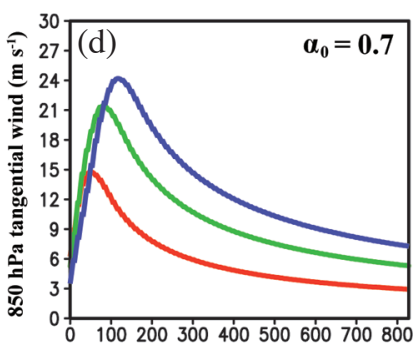

radial distance from eye $(\mathrm{km})$

Fig. 1. Symmetric component of the $850-\mathrm{hPa}$ wind speed $\left(\mathrm{m} \mathrm{s}^{-1}\right)$ for the $36 \mathrm{~km}$ resolution experiments constructed from vortex following composites at the initial time. Panels (a) - (d) show variations with respect to $\mathrm{R}_{\mathrm{m} 0}$; (e) - (g) show variations with respect to $\alpha_{0}$.

Table 3. Same as Table 1, but for the $3 \mathrm{~km}$ experiments, with the outer region being $7.5 \leq R / R_{m} \leq 15$.

\begin{tabular}{|c|c|c|c|c|c|c|c|c|c|c|c|}
\hline \multicolumn{2}{|c|}{ Experiment Name } & \multirow[t]{2}{*}{$\begin{array}{c}\mathbf{R}_{\mathrm{m} 0} \\
(\mathbf{k m})\end{array}$} & \multirow{2}{*}{$\begin{array}{c}\mathbf{R}_{\mathrm{m}} \\
\text { (final } \\
\text { period) } \\
(\mathbf{k m}) \\
\end{array}$} & \multirow[t]{2}{*}{$\begin{array}{c}\mathbf{V}_{\mathrm{m} 0} \\
\left(\mathrm{~m} \mathrm{~s}^{-1}\right)\end{array}$} & \multirow{2}{*}{$\begin{array}{c}V_{\mathrm{m}} \\
\text { (final } \\
\text { period) } \\
\left(\mathrm{m} \mathrm{s}^{-1}\right)\end{array}$} & \multicolumn{2}{|c|}{$\begin{array}{c}\text { Initial } \\
\text { Adjusted Rankine Fit }\end{array}$} & \multicolumn{2}{|c|}{$\begin{array}{c}\text { Final period } \\
\text { Adjusted Rankine Fit }\end{array}$} & \multicolumn{2}{|c|}{$\begin{array}{c}\text { Final period } \\
\text { Adjusted } \\
\text { DeMaria87 Fit } \\
\end{array}$} \\
\hline $\mathbf{R}_{\mathrm{m} 0}$ & $\alpha_{0}$ & & & & & $\alpha$ & $\gamma$ & $\alpha$ & $\gamma$ & c & d \\
\hline bubble & --- & --- & 39.3 & 0 & 65.6 & --- & --- & 1.19 & 3.31 & 0.24 & 0.20 \\
\hline \multirow{4}{*}{$40 \mathrm{~km}$} & 0.5 & 45.0 & 39.3 & 26.4 & 79.6 & 0.50 & 1.07 & 0.97 & 1.92 & 0.14 & 0.09 \\
\hline & 0.625 & 43.2 & 39.6 & 26.0 & 73.0 & 0.625 & 1.11 & 0.98 & 1.93 & 0.14 & 0.09 \\
\hline & 0.75 & 42.3 & 35.7 & 25.4 & 72.0 & 0.75 & 1.13 & 1.04 & 2.28 & 0.17 & 0.12 \\
\hline & 0.9 & 40.5 & 38.7 & 25.0 & 59.3 & 0.90 & 1.19 & 1.16 & 2.88 & 0.21 & 0.16 \\
\hline
\end{tabular}



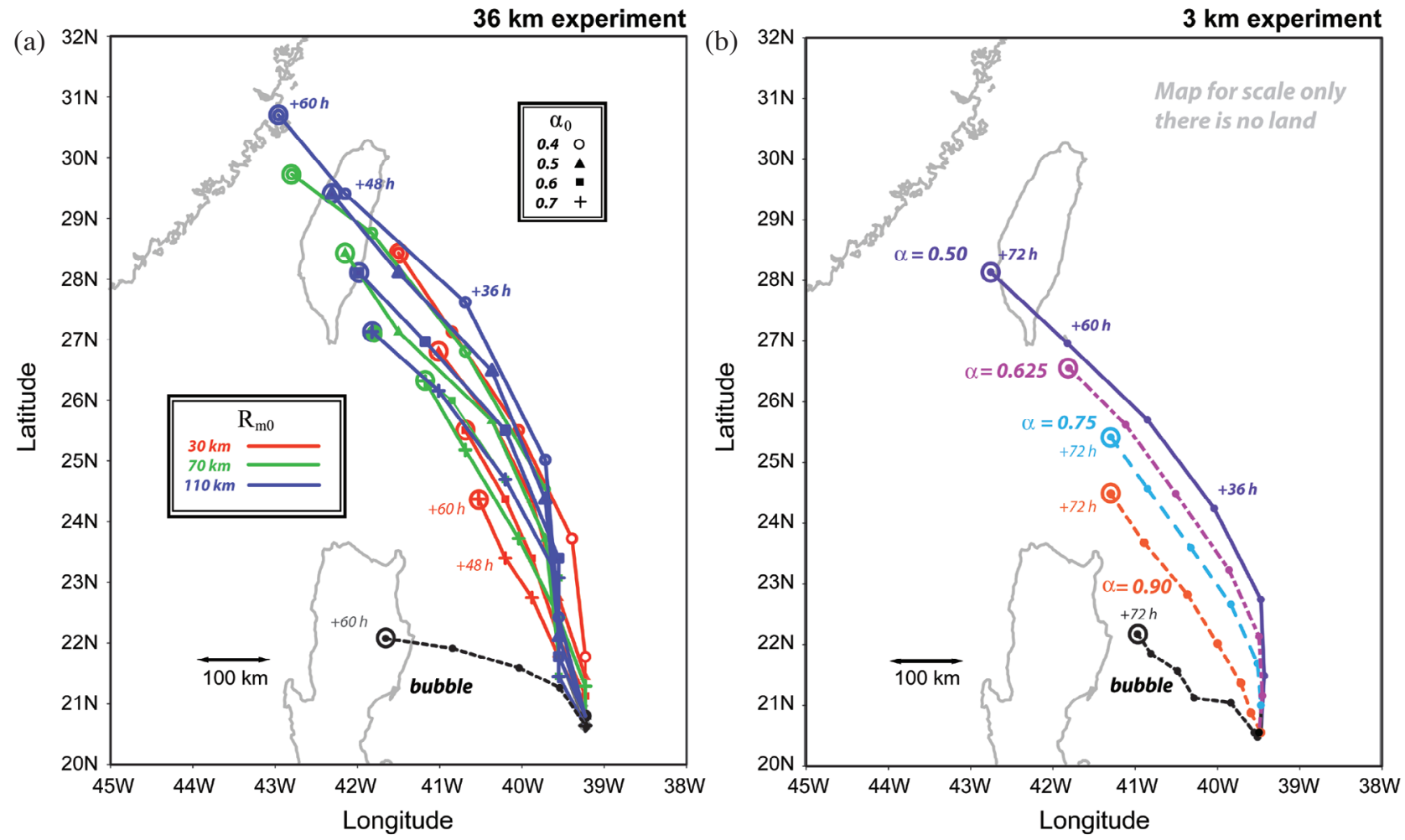

Fig. 2. Twelve-hourly positions (representing geometric centroids of sea level pressure) for the (a) $36 \mathrm{~km}$ resolution experiments (over $60 \mathrm{~h}$ ), and (b) $3 \mathrm{~km}$ resolution experiments (over $72 \mathrm{~h}$ ). The map is shown for scale only; there is no land. Final positions are circled.
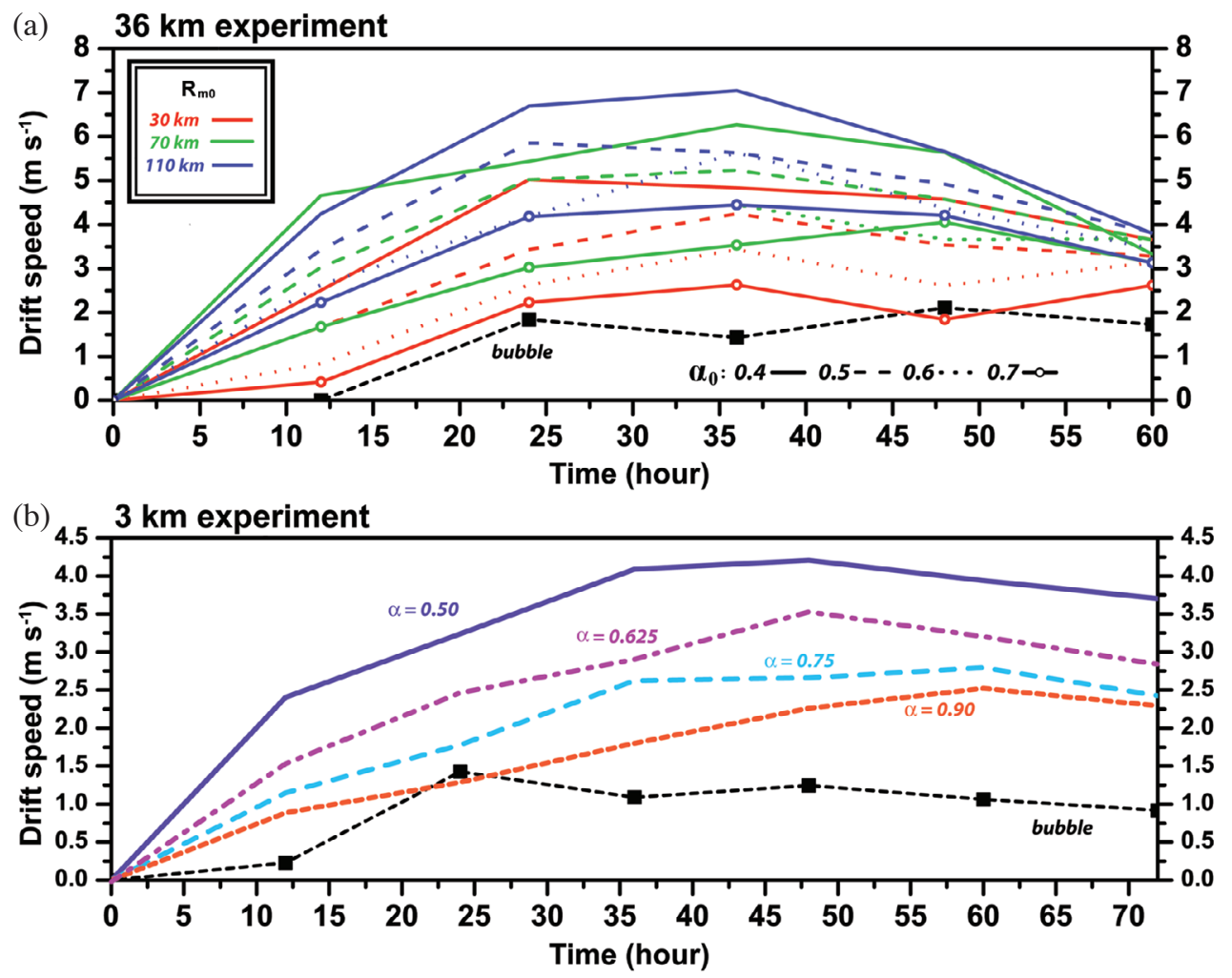

Fig. 3. Time series of TC motion (drift speed; $\mathrm{m} \mathrm{s}^{-1}$ ) for (a) $36 \mathrm{~km}$ resolution, and (b) $3 \mathrm{~km}$ resolution experiments. The values shown are averaged over the prior $12 \mathrm{~h}$ period at that point. Note different horizontal and vertical scales are used. 


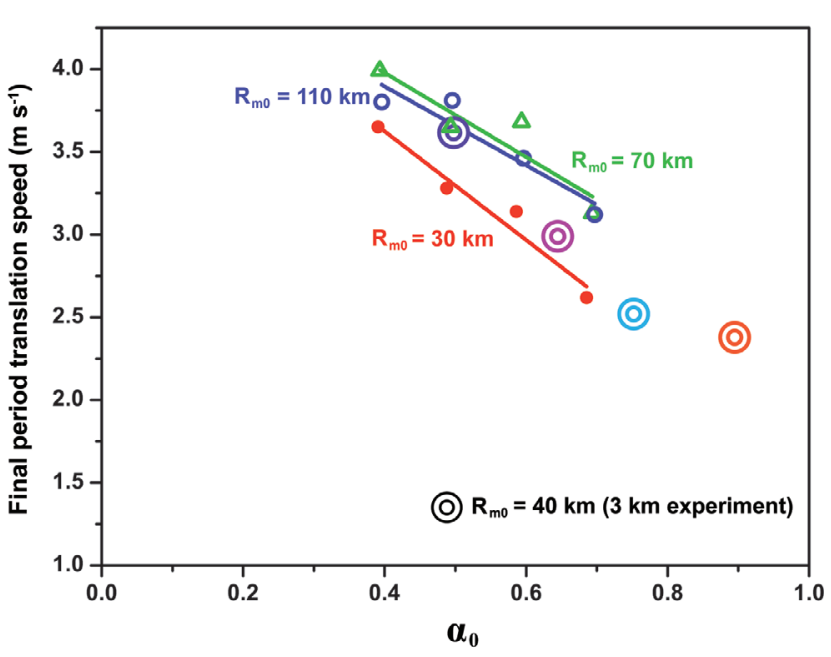

Fig. 4. TC final period translation speed $\left(\mathrm{m} \mathrm{s}^{-1}\right)$ vs initial MR decay factor $\left(\alpha_{0}\right)$. Least squares fits are shown for $36 \mathrm{~km}$ experiment groups distinguished by $\mathrm{R}_{\mathrm{m} 0}$ (small solid circles, triangles and open circles represent coarse resolution $\mathrm{R}_{\mathrm{m} 0}=30,70$, and $110 \mathrm{~km}$ experiments, respectively; large concentric circles represent fine resolution storms).

TCs had appeared to be outliers in those previous studies. Even the fastest moving cyclones in these experiments had only moderate motions compared to observations (e.g., Shea and Gray 1973; Franklin et al. 1996; Corbosiero and Molinari 2003), but it should again be recalled that there is no imposed large-scale steering here.

The bubble TCs took longer to organize and differences in the nature and length of the developmental period impede direct comparisons with the bogussed storms. That said, note in both experiments the bubble TCs had acquired their final translation speeds by about $24 \mathrm{~h}$ into the simulation (Fig. 3). In other words, their slow mature phase motion characteristics were established by the conclusion of what was termed the spin-up period (and entirely neglected) in our previous work (e.g., Fovell et al. 2009, 2010). We specifically address the difference between bubble and bogussed TC translation speed in subsection (d), below.

\subsection{Intensity and Size Evolution}

After initialization, the $36 \mathrm{~km}$ experiment's storms progressively strengthened (Fig. 5a), an apparently common characteristic in idealized TC simulations (e.g., Rotunno and Emanuel 1987; Bender et al. 1993; Frank and Ritchie 1999; Qiu et al. 2010; Xu and Wang 2010, and many others). As the intensification rate was roughly similar among the storms, the final intensities were strongly dependent on initial strength, $\mathrm{V}_{\mathrm{m} 0}$, and thereby carried forward the initial disadvantages exhibited particularly in the $\mathrm{R}_{\mathrm{m} 0}=30$ km TCs (Fig. 6) and the bubble case. The better resolved $3 \mathrm{~km}$ experiment's storms also exhibited temporal strengthening (Fig. 5c), and while they started without a material resolution-induced bias, the maximum wind strength during maturity developed a marked dependence on $\alpha_{0}$ (Table 3 ). The $\alpha_{0}=0.5$ TC's final intensity at $850 \mathrm{hPa}$ was $80 \mathrm{~m} \mathrm{~s}^{-1}$, $33 \%$ stronger than the $60 \mathrm{~m} \mathrm{~s}^{-1}$ rather quickly attained by the case with the most rapidly decaying initial wind profile. With respect to near-surface (10 $\mathrm{m}$ above mean sea level) wind speeds (not shown), that is the difference between a major (Category 3) and a minor (between Categories 1 - 2) hurricane on the Saffir-Simpson scale.

This suggests that improved initialization in the outer wind region might actually affect intensity forecasts, although the physical linkage between the two is not entirely clear and a more comprehensive experiment is needed. More certain is the fact that the environment could support stronger TCs than were initially provided. This suggests that initial vortex intensity should be reconsidered, particularly if skillful intensity prediction is the goal.

With respect to the radius of maximum wind, $R_{m}$, the TCs rather swiftly evolved towards uniformity in the $36 \mathrm{~km}$ experiment (Fig. 5b), with the relatively large $(75-110 \mathrm{~km})$ final period sizes likely representing the influence of the coarse resolution and model physics, particularly the CP. In the $3 \mathrm{~km}$ experiment, in which the model storms were much better resolved and a convective parameterization was not used, all three bogussed vortices contracted considerably in the first few hours, after which they slowly expanded to recover their original $40 \mathrm{~km} \mathrm{R}_{\mathrm{m} 0}$ by $72 \mathrm{~h}$ (Fig. $5 \mathrm{~d}$ ). Experience with the bubble initialization suggests that the convective parameterization helps resist initial vortex contraction; it does not require grid-scale saturation for latent heat generation and the heating the $\mathrm{CP}$ generates is typically spread more widely. The bubble case in this experiment also evolved a $40 \mathrm{~km} \mathrm{R}$ by around $33 \mathrm{~h}$, comparable to the initial and final $R_{m}$ values of the bogussed TCs, and maintained that size for the balance of the simulation. Expansion of the $3 \mathrm{~km}$ experiment to include other initial storm sizes is left for future work.

\subsection{Evolution of Vortex Radial Structure}

This subsection examines the model storms' radial structure, as represented by the symmetric component of the $850 \mathrm{hPa}$ tangential wind. This was computed at the initial time and in a vortex-following fashion for the final $12 \mathrm{~h}$ period as well as for six-hourly intervals in between.

\subsubsection{Near-Core Wind Structure}

Although the outer region is the main focus of this study, examination of the inner core is needed for evaluation and calibration relative to Mallen et al.'s (2005) comprehensive survey of near-core TC wind profiles. Here, however, the near-core is defined as $1.5 \leq \mathrm{R} / \mathrm{R}_{\mathrm{m}} \leq 3.5$ in the $3 \mathrm{~km}$ experiment, and $2 \leq \mathrm{R} / \mathrm{R}_{\mathrm{m}} \leq 4$ in the coarser ensemble, 

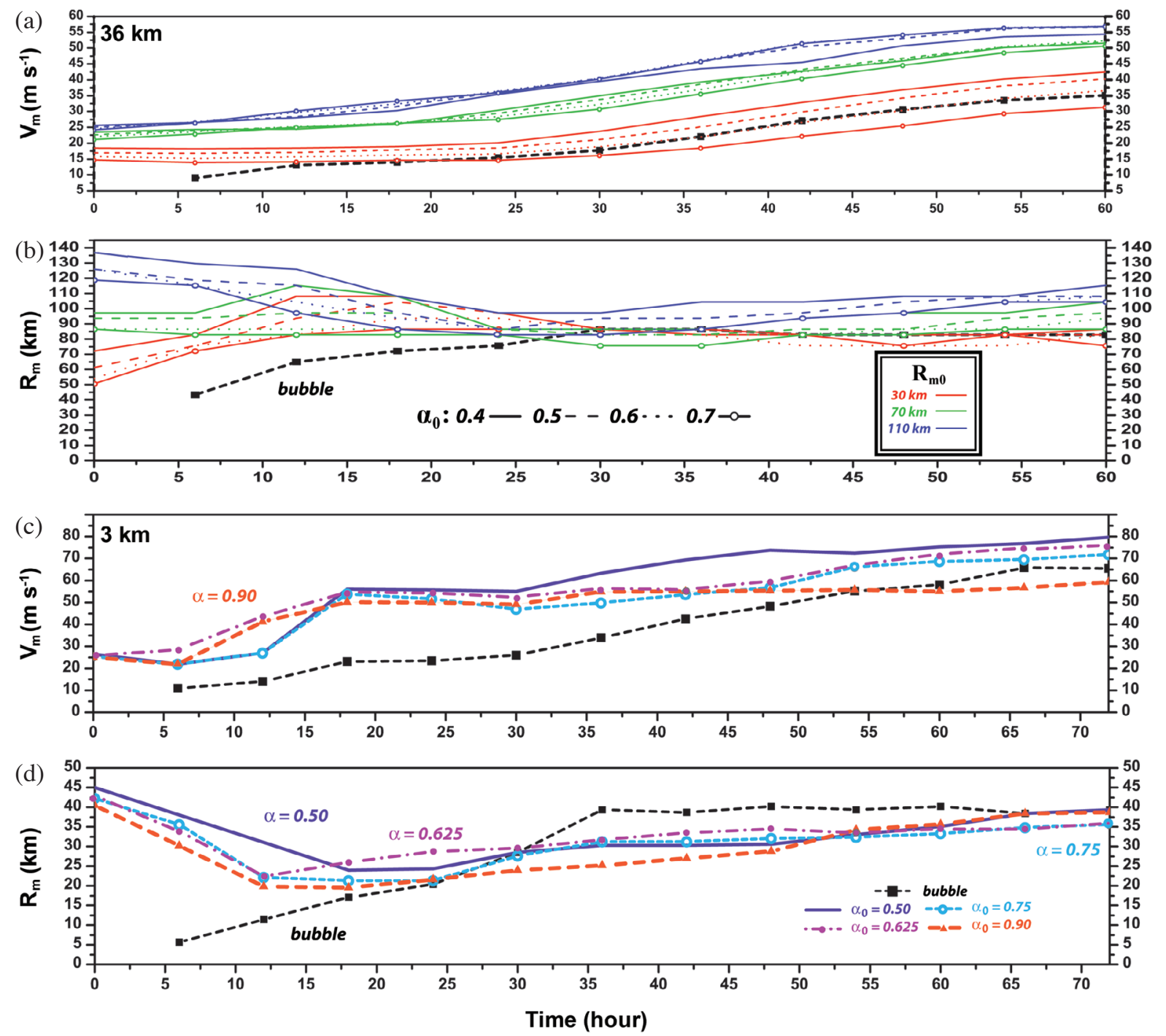

Fig. 5. Time series of $\mathrm{V}_{\mathrm{m}}\left(\mathrm{m} \mathrm{s}^{-1}\right)$ and $\mathrm{R}_{\mathrm{m}}(\mathrm{km})$ for the $36 \mathrm{~km}$ [panels (a), (b)] and the $3 \mathrm{~km}$ [panels (c), (d)] resolution TCs. After the initial time, all plotted values represent averages over the prior $6 \mathrm{~h}$ period, except for the final time shown, which was a $12 \mathrm{~h}$ average.

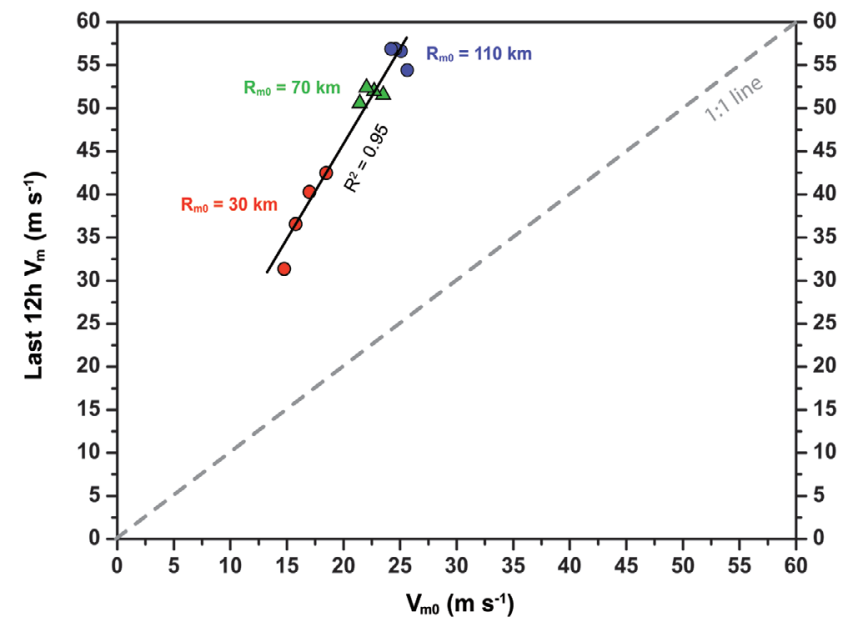

Fig. 6. Final period $\mathrm{V}_{\mathrm{m}}\left(\mathrm{m} \mathrm{s}^{-1}\right)$ vs initial $\mathrm{V}_{\mathrm{m} 0}\left(\mathrm{~m} \mathrm{~s}^{-1}\right)$ for the $36 \mathrm{~km}$ resolution experiment's TCs. to exclude the flatter segment near the $\mathrm{R}_{\mathrm{m}}$ that cannot be adequately treated by any intrinsically convex function. Emphasis is placed on the $3 \mathrm{~km}$ cases, for which this zone is far better resolved.

Initial and final fits of the non-dimensional form of a more general adjusted Rankine (AR) function

$\frac{\mathrm{V}(\mathrm{R})}{\mathrm{V}_{\mathrm{m}}}=\gamma\left(\frac{\mathrm{R}}{\mathrm{R}_{\mathrm{m}}}\right)^{-\alpha}$

for both experiments are reported in Table 4, parameters $\alpha$ and $\gamma$ having been determined via least squares fits. The expected value of the included "adjustment factor" $\gamma$ is unity, but is treated here as a free parameter to improve the reconstructions. Without it, the fits' errors can be systematic functions of $\mathrm{R}$, even at the initial time owing to resolution 
Table 4. AR and AD fit parameters for the near-core $850 \mathrm{hPa}$ symmetric tangential wind in the $36 \mathrm{~km}\left(2 \leq \mathrm{R} / \mathrm{R}_{\mathrm{m}} \leq 4\right)$ and $3 \mathrm{~km}\left(1.5 \leq \mathrm{R} / \mathrm{R}_{\mathrm{m}} \leq 3.5\right)$ experiments.

\begin{tabular}{|c|c|c|c|c|c|c|c|c|}
\hline \multicolumn{3}{|c|}{ Experiment Name } & \multicolumn{2}{|c|}{$\begin{array}{c}\text { Initial time Adjusted } \\
\text { Rankine Fit }\end{array}$} & \multicolumn{2}{|c|}{$\begin{array}{c}\text { Final period Adjusted } \\
\text { Rankine Fit }\end{array}$} & \multicolumn{2}{|c|}{$\begin{array}{c}\text { Final period Adjusted } \\
\text { DeMaria87 Fit }\end{array}$} \\
\hline Resolution & $\mathbf{R}_{\mathrm{m} 0}$ & $\alpha_{0}$ & $\alpha$ & $\gamma$ & $\alpha$ & $\gamma$ & c & d \\
\hline \multirow{13}{*}{$\begin{array}{c}36 \mathrm{~km} \\
\left(2 \leq \mathrm{R} / \mathrm{R}_{\mathrm{m}} \leq 4\right)\end{array}$} & bubble & --- & --- & --- & 0.78 & 1.23 & 0.24 & 0.17 \\
\hline & \multirow{4}{*}{$30 \mathrm{~km}$} & 0.4 & 0.38 & 1.13 & 0.71 & 1.22 & 0.24 & 0.18 \\
\hline & & 0.5 & 0.46 & 1.17 & 0.71 & 1.21 & 0.24 & 0.18 \\
\hline & & 0.6 & 0.56 & 1.26 & 0.68 & 1.25 & 0.28 & 0.23 \\
\hline & & 0.7 & 0.65 & 1.32 & 0.65 & 1.27 & 0.31 & 0.26 \\
\hline & \multirow{4}{*}{$70 \mathrm{~km}$} & 0.4 & 0.39 & 1.10 & 0.78 & 1.22 & 0.23 & 0.17 \\
\hline & & 0.5 & 0.49 & 1.12 & 0.79 & 1.19 & 0.20 & 0.14 \\
\hline & & 0.6 & 0.58 & 1.17 & 0.78 & 1.15 & 0.17 & 0.11 \\
\hline & & 0.7 & 0.69 & 1.22 & 0.76 & 1.18 & 0.20 & 0.14 \\
\hline & \multirow{4}{*}{$110 \mathrm{~km}$} & 0.4 & 0.39 & 1.06 & 0.81 & 1.24 & 0.25 & 0.18 \\
\hline & & 0.5 & 0.49 & 1.11 & 0.83 & 1.20 & 0.21 & 0.14 \\
\hline & & 0.6 & 0.59 & 1.12 & 0.84 & 1.22 & 0.23 & 0.16 \\
\hline & & 0.7 & 0.69 & 1.16 & 0.84 & 1.18 & 0.19 & 0.12 \\
\hline \multirow{5}{*}{$\begin{array}{c}3 \mathrm{~km} \\
\left(1.5 \leq \mathrm{R} / \mathrm{R}_{\mathrm{m}} \leq 3.5\right)\end{array}$} & bubble & --- & --- & --- & 0.54 & 1.02 & 0.03 & 0.02 \\
\hline & \multirow{4}{*}{$40 \mathrm{~km}$} & 0.5 & 0.49 & 1.06 & 0.64 & 1.05 & 0.09 & 0.06 \\
\hline & & 0.625 & 0.62 & 1.10 & 0.67 & 1.08 & 0.13 & 0.09 \\
\hline & & 0.75 & 0.74 & 1.12 & 0.68 & 1.06 & 0.10 & 0.06 \\
\hline & & 0.9 & 0.89 & 1.18 & 0.66 & 1.09 & 0.17 & 0.12 \\
\hline
\end{tabular}

and interpolation issues. Note that while the decay parameters retrieved from the initializations closely matched the requested values, the initial adjustment factors clearly increased as the initial artificial vortex became relatively less well-resolved (i.e., higher $\alpha_{0}$ and/or smaller $\mathrm{R}_{\mathrm{m} 0}$ ). That said, the initial values are not unacceptably different from expected.

The AR function (4) provided extremely skillful fits to the near-core wind profile for the final period, especially for the high-resolution bogussed cases (Figs. 7a - c). The adjustment factor $\gamma$ for the $3 \mathrm{~km}$ bogussed TCs drifted towards the expected value throughout the simulation (Fig. 8b), although by the final time the pure MR profile was still a little too flat (e.g., Fig. 7c). The artificial cyclones' initial convex shape, however, was not preserved. Despite different initial decay parameters ranging between $0.5-0.9$, the $3 \mathrm{~km}$ TCs evolved near-core profiles of nearly identical, moderate sharpness (Fig. 8a), with the final fits of $0.66 \pm 0.02$ (Table 4) falling well within the Mallen et al. (2005) range. Note that the final period wind profiles (Fig. 9b) resemble each other more than they do with the initially supplied structures (Fig. 9a), especially when nondimensionalized (Fig. 9c). This is another instance of the progressive homogenization seen in these experiments.

In the coarser resolution ensemble (Table 4), final period adjustment factors generally remained around $\gamma \sim 1.2$, which seems reasonably close to unity. All final period $\alpha$ values not only exceeded $\alpha_{0}$ but also ended up above the upper bound of the Mallen et al. (2005) observations (0.67). Thus, material sharpening of the originally supplied MR profiles has occurred, leading to homogenization (compare Fig. 10 with Fig. 1). Note further that the final decay parameter depended far more on $\mathrm{R}_{\mathrm{m} 0}$ than on $\alpha_{0}$, and that the better resolved the $\mathrm{TC}$, the sharper its final near-core profile (compare Tables 1 and 4). Beyond relevant resolution issues, the role of the convective parameterization in this result should be investigated, as this is a major difference between the two experiments.

It is important to note that the bubble runs also developed Rankine vortex structures in the near-core region, in both the $3 \mathrm{~km}$ (Figs. 7d, 9c) and $36 \mathrm{~km}$ (not explicitly demonstrated) versions. Moreover, the bubble runs acquired decay and adjustment parameters quite comparable to those eventually established in their bogussed counterparts, i.e., their dimensionless profiles become rather sharp and more moderate for the coarse and fine resolution cases, respectively. In particular, the $3 \mathrm{~km}$ bubble TC not only evolved the purest form of (4) - i.e., with $\gamma \sim 1$ - but also established a decay parameter that came closest to the expected value of 0.5 (e.g., Riehl 1963; Emanuel 1986). This is an interesting, although possibly coincidental finding.

More importantly, as no specific wind structure was imposed on these simulations by the nature of the initialization, the bubble results imply that powerful forces, possibly involving vortex dynamics, environment, model physics, resolution, or combinations thereof, worked to determine 
Final period near-core winds

(a)

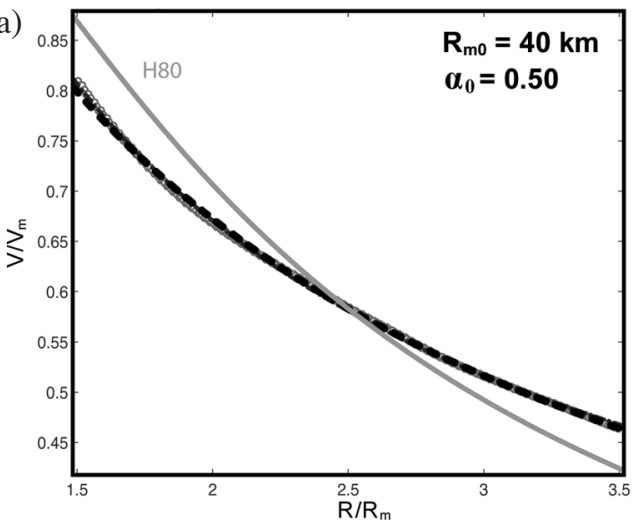

(b)

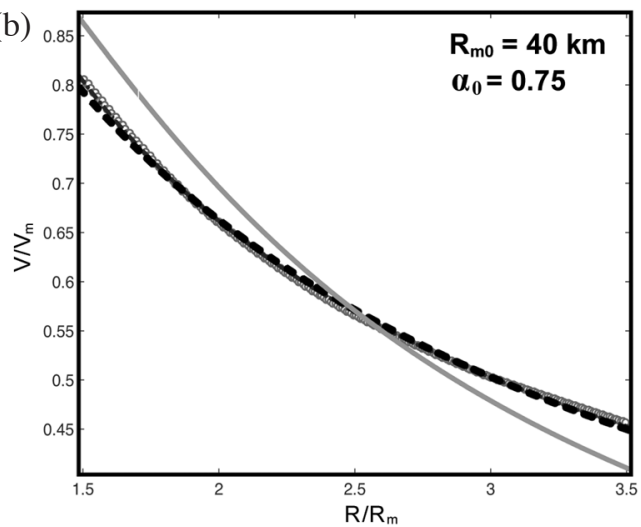

(c)

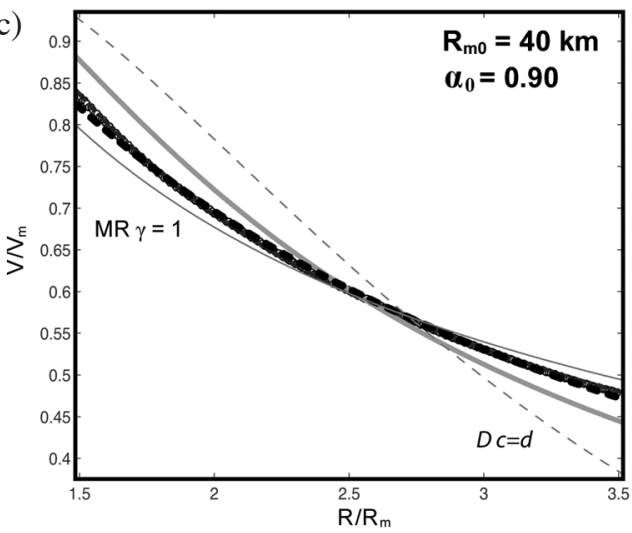

(d)

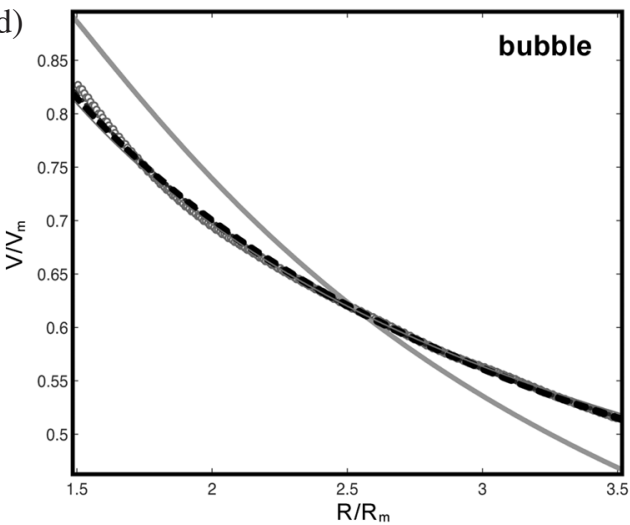

Final period outer winds
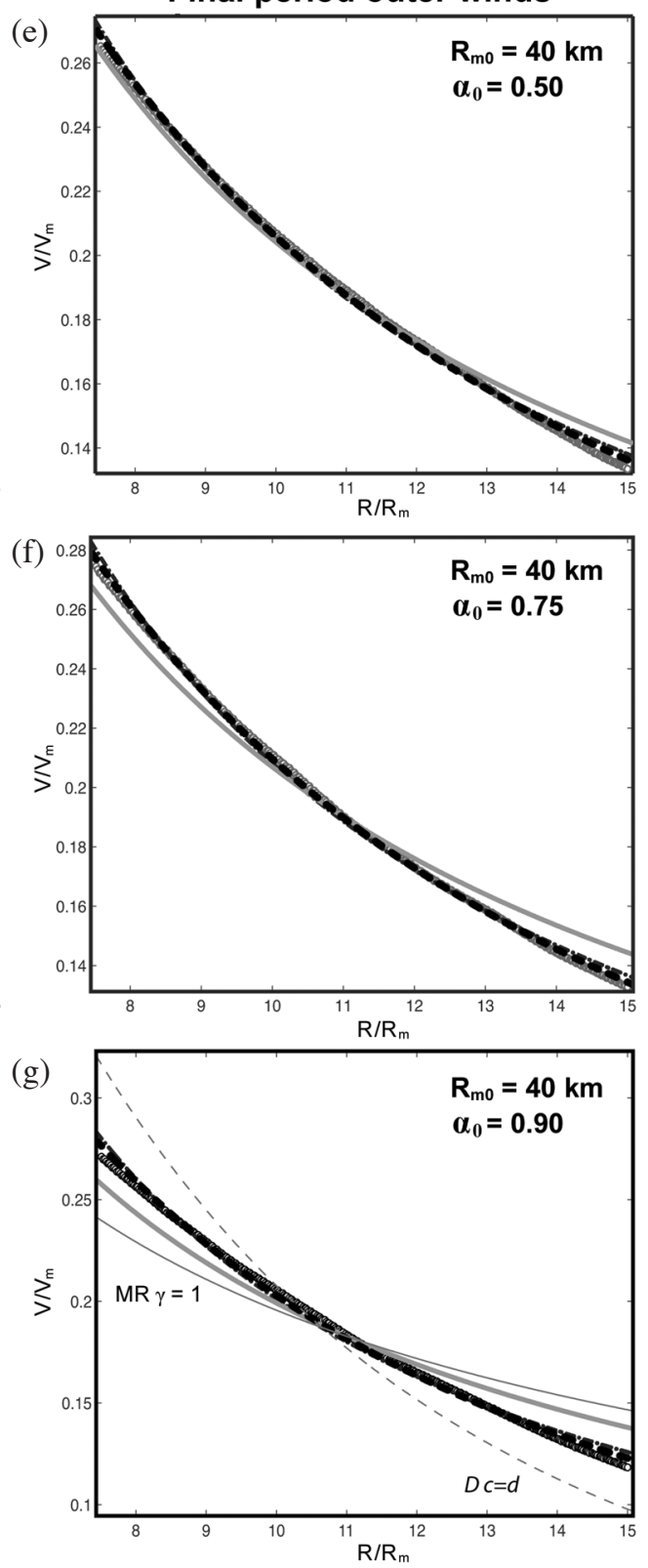

(h)

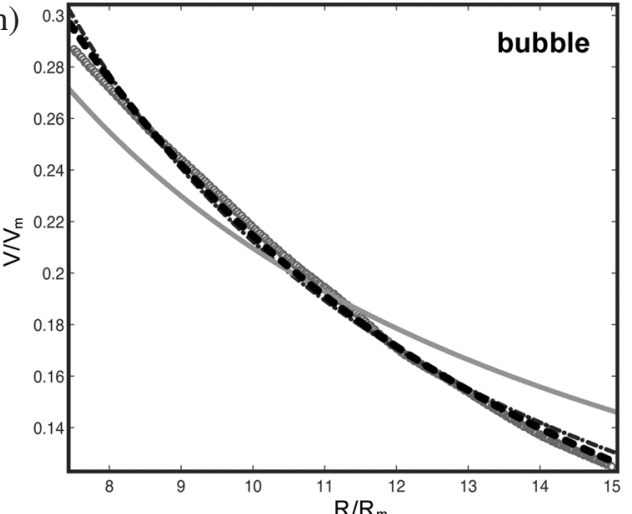

$000000850 \mathrm{hPa}$ symmetric winds -.-.- adjusted Rankine fit Holland 1980 fit - - - adjusted DeMaria 1987 fit

Fig. 7. Non-dimensionalized fits of several parametric wind profile (AR, H80 and AD) forms to the symmetric component of final period $850 \mathrm{hPa}$ $\mathrm{V} / \mathrm{V}_{\mathrm{m}}$ with respect to $\mathrm{R} / \mathrm{R}_{\mathrm{m}}$ for selected $3 \mathrm{~km}$ TCs for the (a) - (d) near-core (1.5 $\leq \mathrm{R} / \mathrm{R}_{\mathrm{m}} \leq 3.5$ ) and (e) - (h) outer (7.5 $\left.\leq \mathrm{R} / \mathrm{R}_{\mathrm{m}} \leq 15\right)$ regions. MR fit $(\gamma=1)$ and DeMaria fit with $\mathrm{c}=\mathrm{d}$ only shown on $(\mathrm{c})$ and $(\mathrm{g})$. 
$3 \mathrm{~km}$ experiment - near-core $\left(1.5 \leq R / R_{m} \leq 3.5\right)$
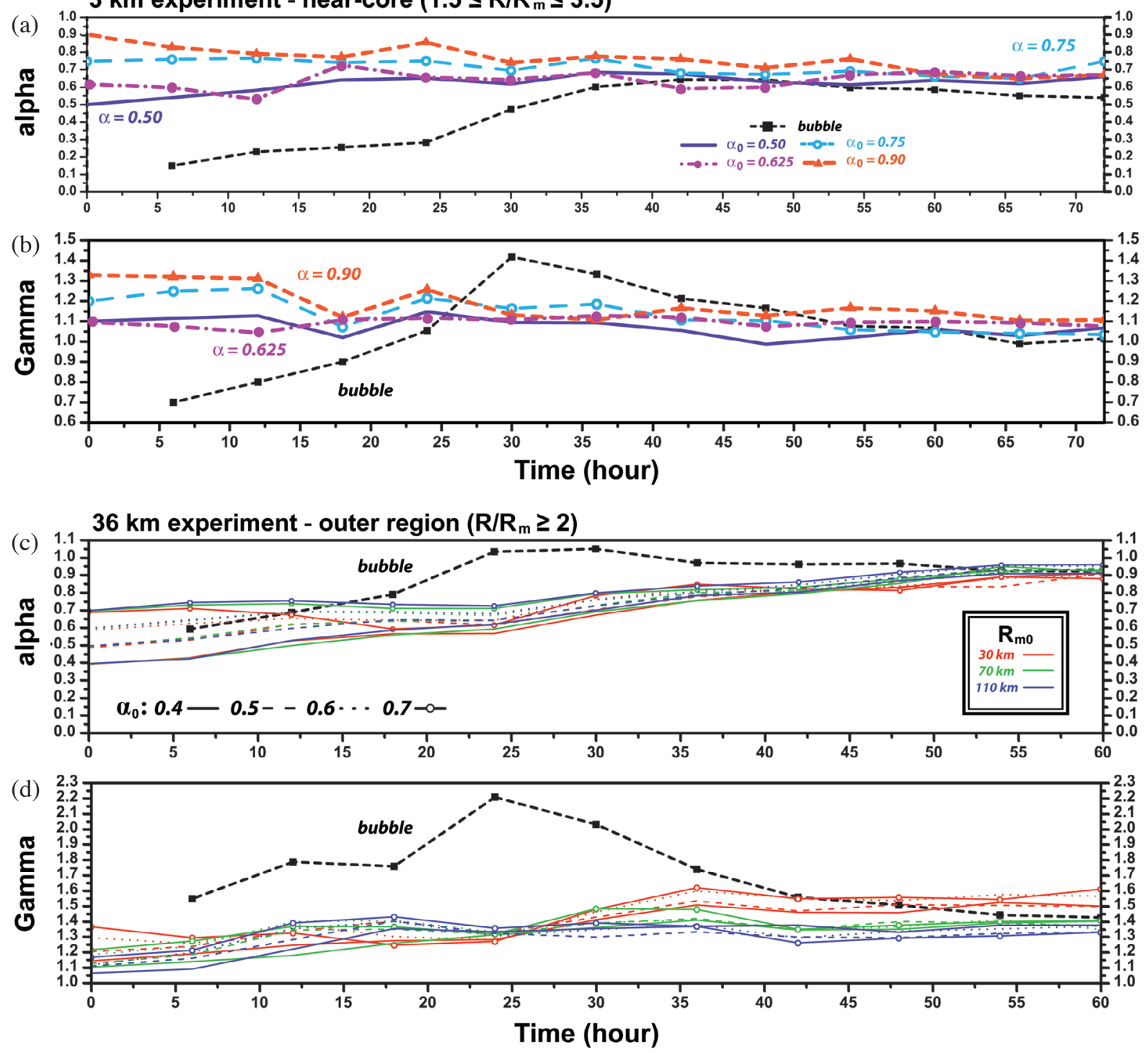

Fig. 8. Time series of AR decay factor $\alpha$ and adjustment factor $\gamma$ for the $3 \mathrm{~km}$ [panels (a), (b)] and $36 \mathrm{~km}$ [panels (c), (d)] resolution experiments .

(a)

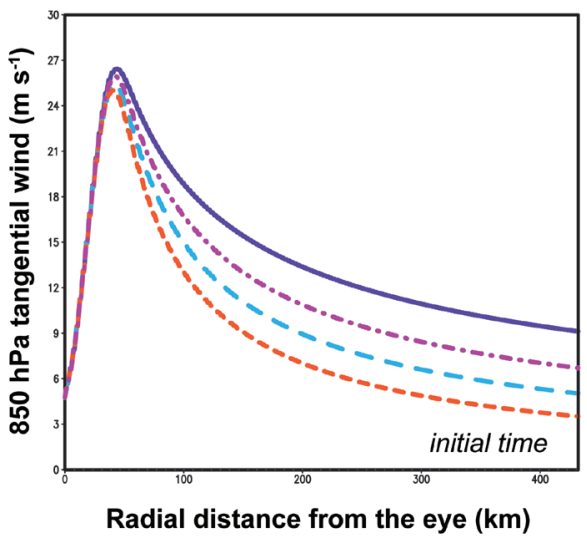

(b)

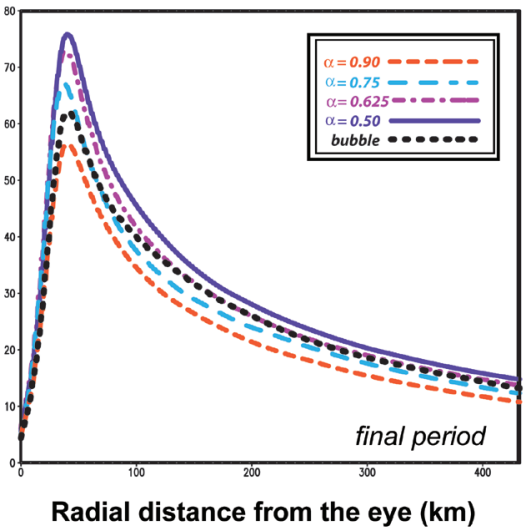

(c)

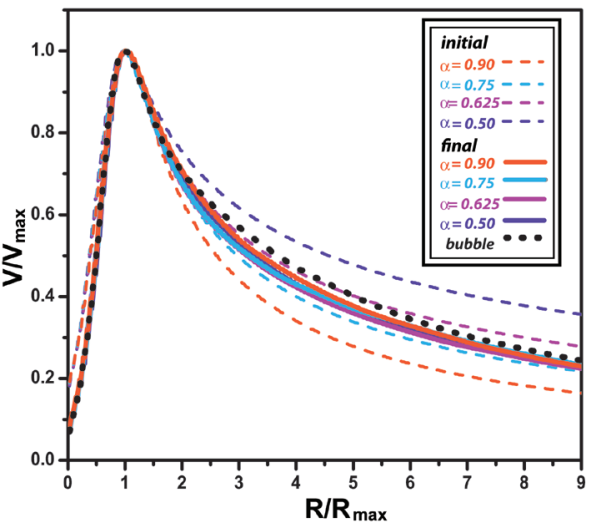

Fig. 9. Symmetric component of the $850-\mathrm{hPa}$ wind speed $\left(\mathrm{m} \mathrm{s}^{-1}\right)$ for the $3 \mathrm{~km}$ resolution experiments constructed from vortex following composites for (a) initial time and (b) final period. Panel (c) contrasts the initial and final nondimensional profiles. 

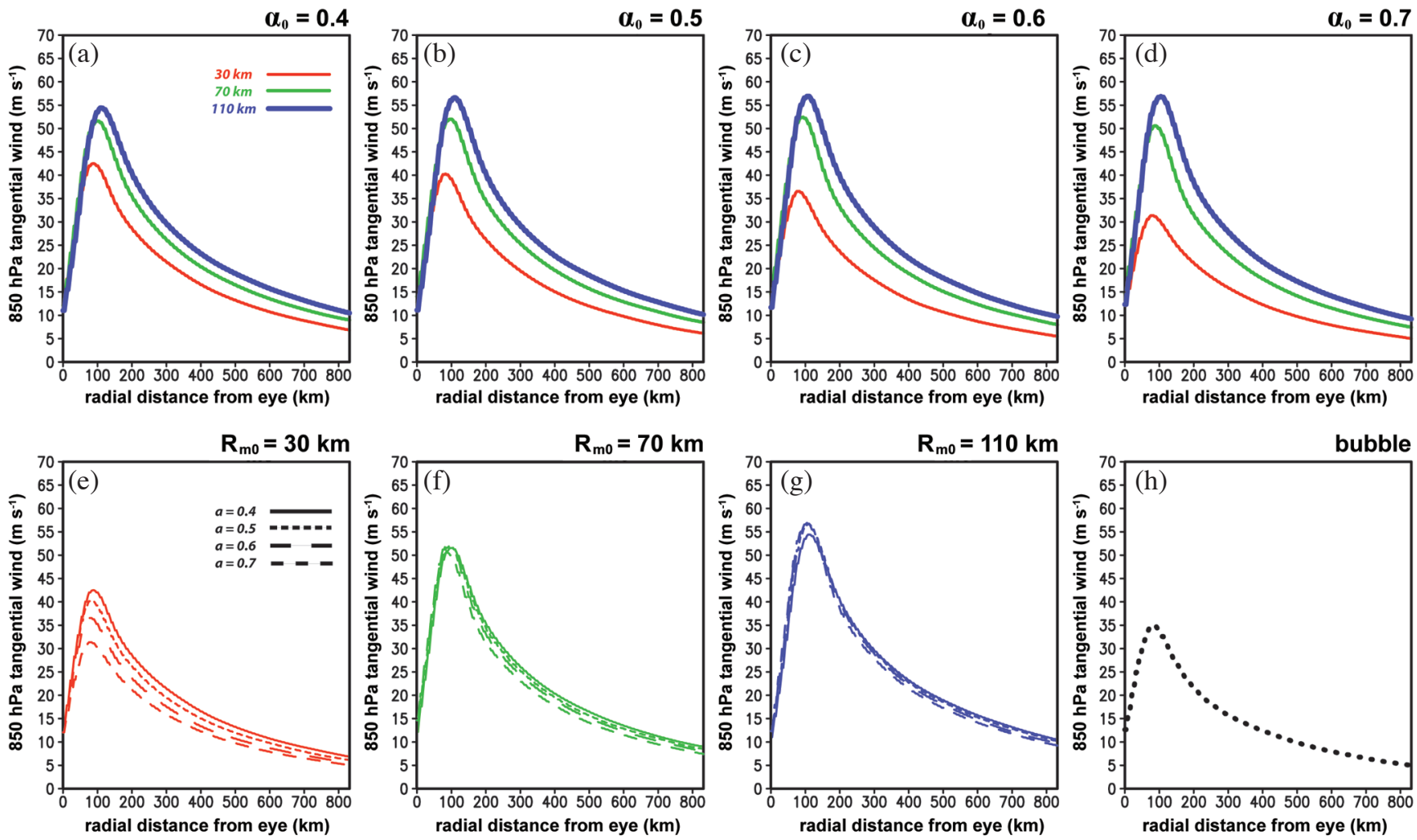

Fig. 10. Symmetric component of the 850-hPa wind speed $\left(\mathrm{m} \mathrm{s}^{-1}\right)$ for the $36 \mathrm{~km}$ resolution experiments constructed from vortex following composites for the final period. Panels (a) - (d) show variations with respect to $R_{m 0}$; (e) - (h) present variations with respect to $\alpha_{0}$.

the near-core wind strength and structure of the simulated TCs during maturity. If the Rankine profile, however modified or adjusted, is not the most optimal or dynamically justifiable structure for the near-core regions of real TCs (e.g., Goerss and Jeffries 1994; Leslie and Holland 1995), this suggests the presence of important model deficiencies, very likely involving the physical parameterizations, that need to be identified and rectified.

\subsubsection{Outer Wind Structure}

The initially provided MR profile extended through the near-core zone to the outer region most relevant to beta drift. To emphasize this region, outer wind reconstructions were also made for the interval $R / R_{m} \geq 2$ (i.e., $R \geq 200 \mathrm{~km}$ ) for the $36 \mathrm{~km}$ simulations (Fig. 11) and the $7.5 \leq \mathrm{R} / \mathrm{R}_{\mathrm{m}} \leq 15$ (about $300-600 \mathrm{~km}$ ) annulus for the more compact, higher resolution TCs (Figs. 7e - h). For the coarser experiment, these reconstructions started at the same nondimensional radius as the fits discussed above but were not truncated at $R / R_{m}=4$, which affects the overall shape and quality of the fits. Again, the initial fits were more accurate for the better resolved artificial vortices (see, especially, Fig. 11b) and did not vary much from the near-core reconstructions (Tables 1,3).
The final period fits of (4) in each case were generally good, remaining so out to a surprisingly large multiple of $R_{m}$ in some cases, especially in the $36 \mathrm{~km}$ experiment (Figs. 11c-d). However, the final reconstructions represent a considerable deviation from not only the initial state but also the modified Rankine structure (1). Among the $36 \mathrm{~km}$ ensemble members, parameter evolution was gradual but persistent through the simulation (Figs. 8c, d). The convergence of their $\alpha$ values into a very narrow range $(0.92$ \pm 0.04 ) for the final period is yet another manifestation of homogenization. The high resolution TCs developed even sharper outer region profiles (Table 3), contrasting with the near-core findings. For the final period outer winds, true MR $(\gamma=1)$ fits were quite poor (Fig. 11c provides an example), demonstrating the limitations noted by Holland (1980), Leslie and Holland (1995), and others. Model TCs do not, and perhaps cannot, preserve their initially supplied structures for large R.

$\mathrm{H} 80$ and $\mathrm{AD}$ functions were also fitted to the final period wind profiles, for both the outer and near-core regions, again via least squares (Figs. 7,11). The H80 formula tended to diminish the winds too quickly outward from the core (especially in the high resolution experiment, Fig. 7), the opposite of the MR tendency. In contrast, the adjusted DeMaria fits were uniformly excellent, nearly always pro- 
viding the best reconstruction in both experiments and for both regions as measured by mean square error, but if and only if parameters $c$ and $d$ were permitted to vary independently. This profile was originally developed to model outer winds (see Fig. 1 in DeMaria 1987), although with the two parameters treated as equivalent.

The authors are unaware of any previous study in which the two parameters were varied independently. With equivalence enforced, the DeMaria function generated considerably poorer reconstructions (e.g., Figs. 7c, g and Figs. 11a, c). Note further that in no case was d ever close to the previously presumed value of one (e.g., Leslie and Holland 1995;
Holland et al. 2010) for the outer region (Tables 1, 3) or the near-core zone (Table 4). Interpretation and intercomparison of these parameter values is presently unclear, but it is recognized that the $\mathrm{AD}$ and $\mathrm{AR}$ coefficients exhibit significant intercorrelations (see, especially, Table 1).

As for the bubble cases, they again evolved to closely resemble their artificially-initiated counterparts, with AR and $\mathrm{AD}$ fits falling within the parameter ranges established by the bogussed storms (Tables 1, 3). Indeed, the $36 \mathrm{~km}$ bubble TC was able to develop a sharp outer wind profile well before that experiment's bogussed cases were able to do so (Fig. 8c), perhaps because it did not have an imposed
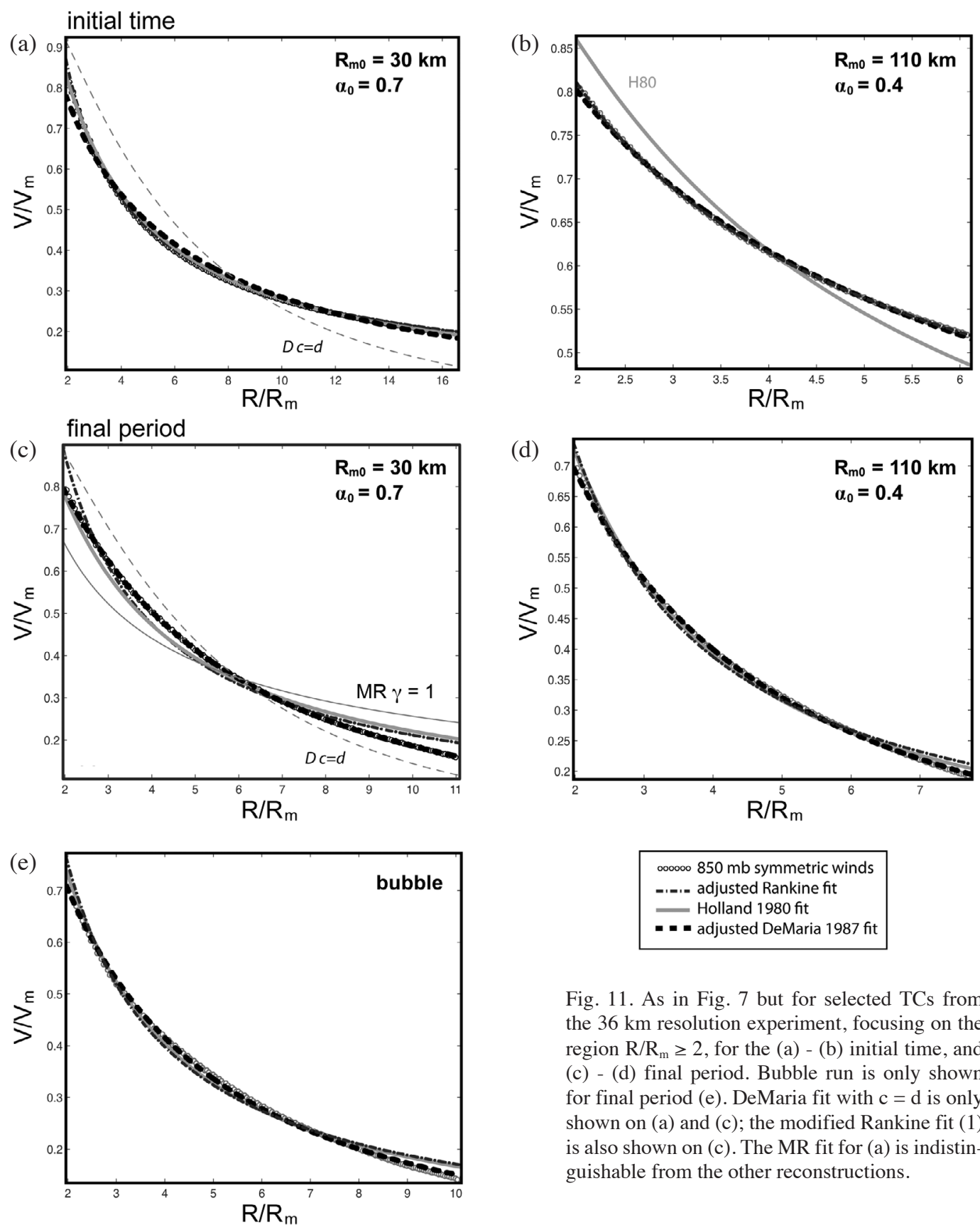

$$
\begin{aligned}
& \text { 000000 } 850 \text { mb symmetric winds } \\
& \text {--- adjusted Rankine fit } \\
& \text { - - - Holland } 1980 \text { fit } \\
& \text { - adjusted DeMaria } 1987 \text { fit }
\end{aligned}
$$

Fig. 11. As in Fig. 7 but for selected TCs from the $36 \mathrm{~km}$ resolution experiment, focusing on the region $R / R_{m} \geq 2$, for the (a) - (b) initial time, and (c) - (d) final period. Bubble run is only shown for final period (e). DeMaria fit with $\mathrm{c}=\mathrm{d}$ is only shown on (a) and (c); the modified Rankine fit (1) is also shown on (c). The MR fit for (a) is indistinguishable from the other reconstructions. 
structure to overcome. It remains to be ascertained just what portion of this tendency towards relative uniformity is determined within, by the model physics.

\subsection{Bubble vs. Bogus Convective Heating Differences}

One important characteristic that has eluded the tendency towards homogenization is the stark difference between the bogussed and bubble-initiated TCs with respect to translation speed that developed and persisted through the experiments. Close inspection of Figs. 10e and h suggests the $36 \mathrm{~km}$ bubble run shared a final period $850 \mathrm{hPa}$ symmetric component wind profile with the $\mathrm{R}_{\mathrm{m} 0}=30 \mathrm{~km} / \alpha_{0}=0.7$ simulation beyond $200 \mathrm{~km}$, although the speed and direction of their motions were quite different (Fig. 2a). Among the $3 \mathrm{~km}$ TCs, the bubble run's wind strength at larger radii was neither strongest nor weakest (Fig. 9b), which fails to hint at its markedly slower translation (Table 2). Naturally, the symmetric component of the wind is also a function of height, and this also varied widely among the coarse resolution experiment's TCs (Fig. 12). Yet again, the bubble run does not appear markedly different from the $\mathrm{R}_{\mathrm{m} 0}=30 \mathrm{~km} / \alpha_{0}$ $=0.7$ case (compare Figs. $12 \mathrm{~d}$ and $\mathrm{m}$ ), despite moving $34 \%$ slower (Table 2).

These model TCs are in motion owing to structural asymmetries and ventilation flow established across the vortex by the latitudinal gradient in planetary vorticity; i.e., the beta drift. Since the TCs are warm core vortices, the ventilation flow should decrease with height (Bender 1997), representing a vertical shear that can encourage asymmetric convection (Frank and Ritchie 1999; Corbosiero and Molinari 2002). Fovell et al. (2010) showed that concentrating convection on one flank of the model storm could materially influence both speed and direction of motion. This was demonstrated via the potential vorticity (PV) analysis strategy of Wu and Wang $(2000,2001)$.

A PV analysis for the $36 \mathrm{~km}$ bubble and $\mathrm{R}_{\mathrm{m} 0}=30 \mathrm{~km} /$ $\alpha_{0}=0.7$ simulations over the final period suggests that convective asymmetries can explain the variation in both translation speed and direction (Figs. 13a, b). Both model TCs have very asymmetric convection, as suggested by their lower tropospheric vertical velocity fields, which represent mass-weighted averages over the lowest $4.3 \mathrm{~km}$. For the bubble and bogus cases, ascent (and convective heating) was concentrated on the southeast and northern flanks, respectively. The PV tendency does not directly reflect diabatic heating itself, but rather its vertical gradient (cf. Wu and Wang 2000), creating PV when and where heating increases with height.

The PV tendency (PVT) may be decomposed as

$\mathrm{PVT}=\Lambda_{1}(\mathrm{HA}+\mathrm{VA}+\mathrm{DH}+\mathrm{R})=\Lambda_{1}\left(\mathrm{HA}+\mathrm{DH}^{*}\right)$ where HA and VA are horizontal and vertical PV advection, $\mathrm{DH}$ is the diabatic contribution from convection (both microphysics and $\mathrm{CP}$ ), $\mathrm{R}$ represents remaining terms, and the operator $\Lambda_{1}$ extracts the wavenumber one component [see Wu and Wang 2000, Eq. (5)]. The magnitude and direction of each term's contribution to the PVT was determined using least squares, again following $\mathrm{Wu}$ and Wang (2000). For this application, the terms DH, VA and R (i.e., DH*) have been combined owing to a significant degree of interaction between the first two. HA and $\mathrm{DH}^{*}$ also strongly influence each other, although at least part of HA should reflect the beta drift itself. The vector $\mathrm{C}$ represents the final period storm motion, which is closely approximated by HA $+\mathrm{DH}^{*}$.

Depending on resolution, the TC itself is either a columnar tube or doughnut-shaped ring of positive PV in the lower troposphere (not shown), so a general storm translation to the northwest implies positive PVT on the northwest side with negative values on the southeast side. In the $36 \mathrm{~km}$ bubble case, the lower tropospheric heating on the southeast flank represents a positive contribution to PVT there, in partial opposition to the beta-induced motion (Fig. 13a). In contrast, both $\mathrm{DH}^{*}$ and $\mathrm{HA}$ are oriented in the direction of storm motion in the $\mathrm{R}_{\mathrm{m} 0}=30 \mathrm{~km} / \alpha_{0}=0.7$ storm, so $\mathrm{PV}$ generation owing to convection is assisting this TC's northwestern propagation. The two $3 \mathrm{~km}$ cases are clearly more compact and possessed more intense and concentrated ascent. In the $3 \mathrm{~km}$ bubble run (Fig. 13c), DH* was even more in opposition with the beta drift, resulting in the slowest motion in either experiment (Table 4). In the highlighted bogussed case from this experiment, DH and VA mutually cancelled, leaving motion completely controlled by horizontal advection of PV (Fig. 13d). This TC had very nearly the fastest translation speed among all the cases.

Previous research, reviewed in Corbosiero and Molinari (2002), has established that ascent can be expected on the downshear side, resulting in enhanced convection to the downshear-left of the vertical shear vector in the eyewall (e.g., Frank and Ritchie 2001). As these simulations started in a quiescent environment, the vertical shear that became established represents the model TCs' interactions with their own environments. As in Bender (1997), the bubbleinitiated runs developed a southeasterly ventilation flow that decreased with height, establishing a northwesterly "beta shear" that encouraged convection on their eastern flanks (Figs. 13a, c). The asymmetric ascent patterns developed here resemble those seen here in previous work (Fovell et al. 2010).

However, for reasons presently unknown, the bogussed vortices developed southerly shears (not shown), consistent with the front-flank convection and asymmetric heating that in these cases acted to support storm motion. Thus, the artificially-induced TCs have acquired a vertical shear that is not only directed oppositely to the beta shear, but also has 
managed to overwhelm it. It is not presently clear why the bogussed and bubble simulations developed in such different ways, and this is a subject for further research.

These are idealized simulations, so there is no single correct answer. However, detailed intercomparison of convective asymmetries in simulations of actual TCs with observations is strongly indicated. The principal result is that, for the purposes of track forecasting, there is a strong sensitivity to the initial condition, with a temporal evolution in storm structure that we suspect is to a large degree internally determined, reflecting model physics as well as artificial aspects of initialization.

\section{CONCLUSIONS}

Aquaplanet, semi-idealized integrations of tropical cyclone vortices demonstrate that the final forecast position is enormously sensitive to the manner in which the TC is handled at the model start time. Tested here were vortices bred within the model from a buoyant perturbation with no imposed wind structure and a suite of modified Rankine vortices specified with a range of realistic wind decay fac- tors, $\alpha$, and maximum wind radii. TC structures for both the near-core and outer region winds during maturity were fitted with a variety of convex shapes, including the adjusted Rankine and adjusted DeMaria profiles, which are more flexible versions of long-established functions. The latter, which consisted of two free parameters, proved especially skillful at fitting wind profiles from the near-core region out to many multiples of the radius of maximum wind.

The results clearly show that subtle changes in the size and shape of the outer wind profile can mean the difference between a faster or slower moving storm, an earlier or later landfall, greater or smaller local precipitation accumulations, and/or a properly or inadequately warned public and evacuated section of the coastline. Despite significant initial differences in storm size and structure, however, a rather unsettling progression towards uniformity with respect to some aspects of storm structure was also documented. As a powerful example, the bogussed vortices could not retain their originally supplied shapes in the outer wind field most relevant to modulating beta drift and storm motion. Instead, the vortices tended to evolve greater commonality with respect to outer wind profile sharpness, which means the
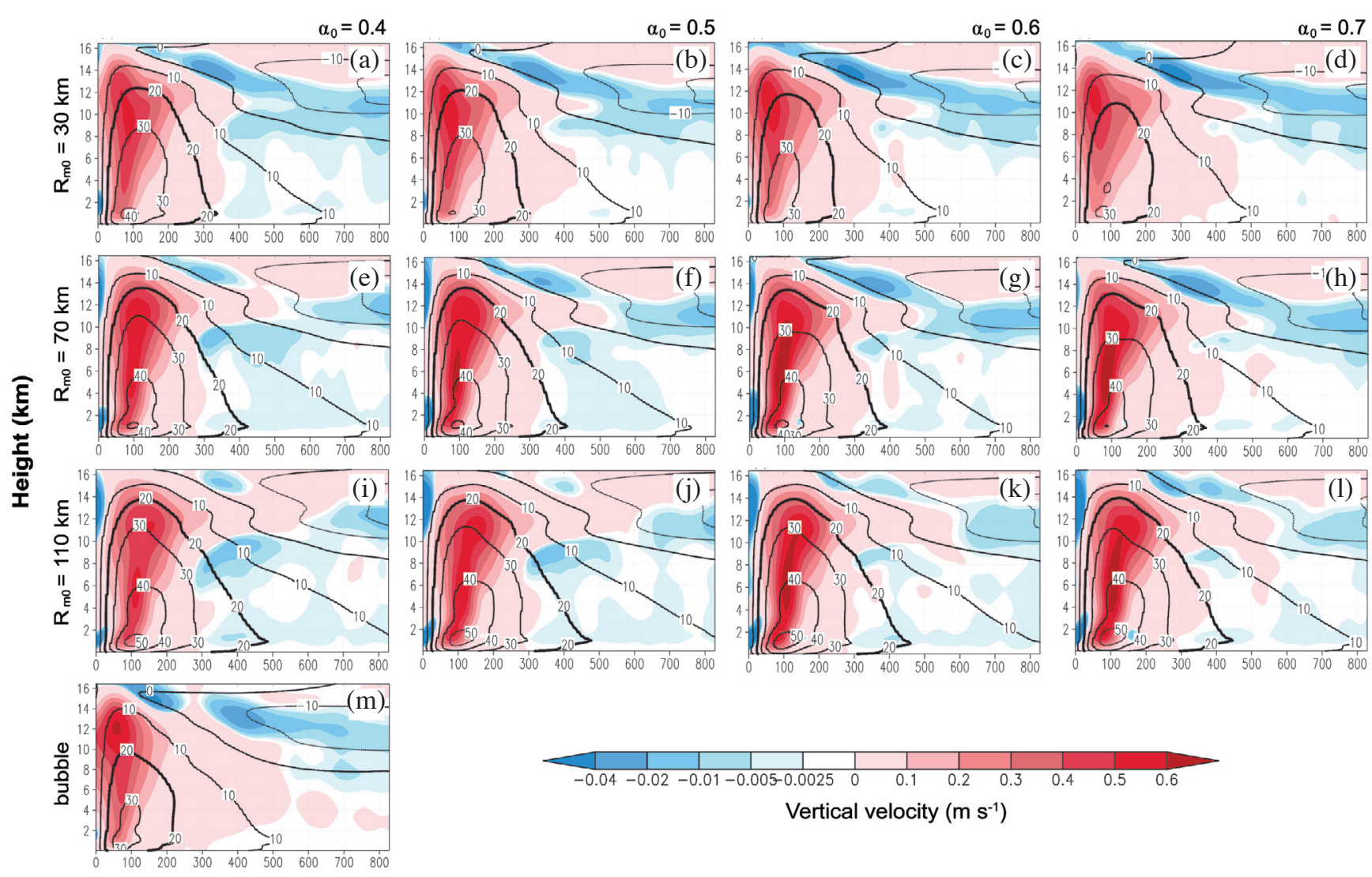

\section{Radial distance from the eye $(\mathrm{km})$}

Fig. 12. Radius-height cross-sections of azimuthally averaged vertical velocity (positive values shaded or colored; negative values colored or contoured at $\left.0.01 \mathrm{~m} \mathrm{~s}^{-1}\right)$ and symmetric component of tangential wind $\left(10 \mathrm{~m} \mathrm{~s}^{-1}\right.$ contours, $20 \mathrm{~m} \mathrm{~s}^{-1}$ contour highlighted), averaged over the final period for the $36 \mathrm{~km}$ experiment ensemble TCs. 

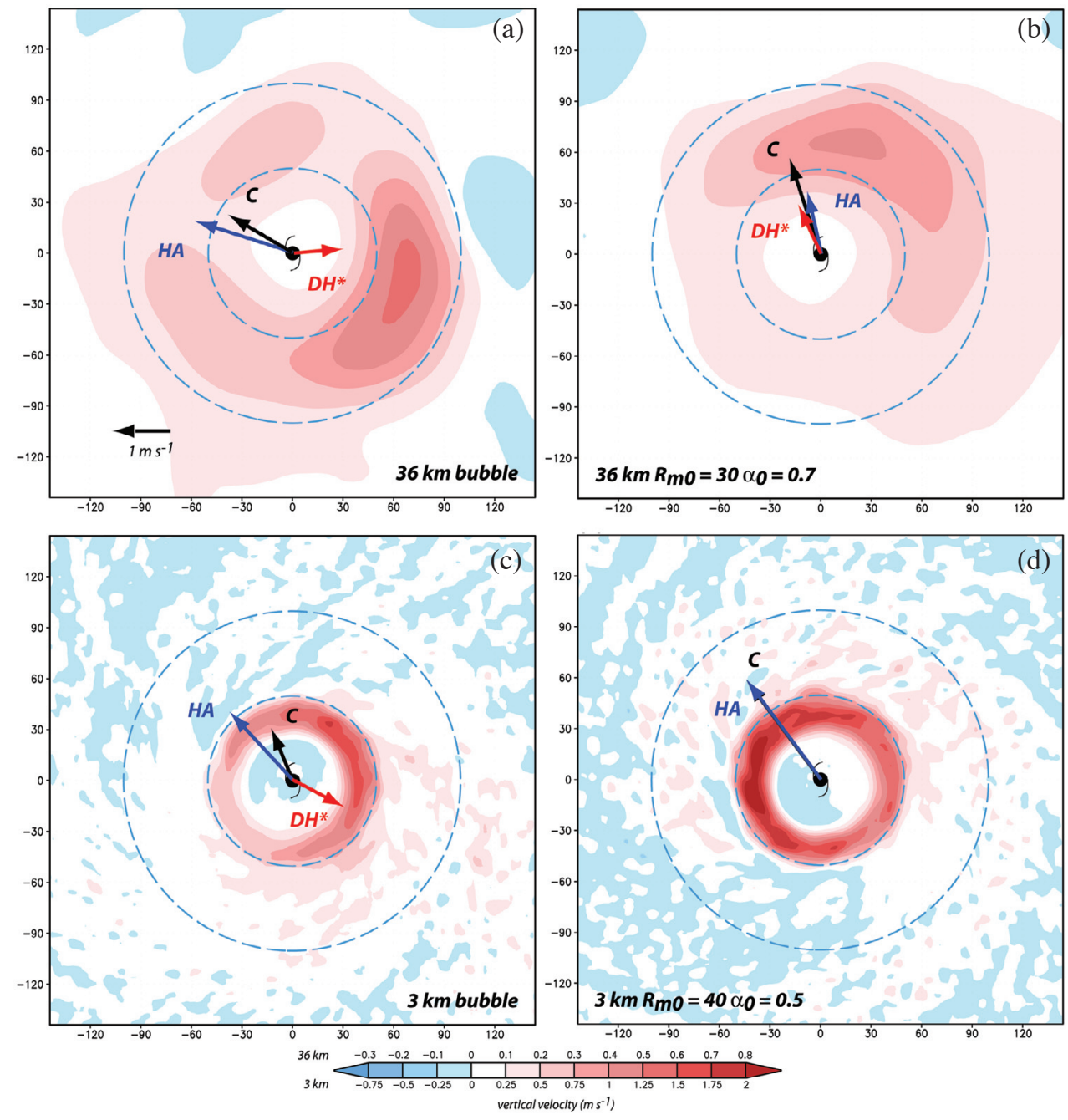

Fig. 13. Mass-weighted vertically-averaged vertical velocity for the lowest $4.3 \mathrm{~km}$ (shaded) for the final period for the $36 \mathrm{~km}$ (a) bubble, and (b) $\mathrm{R}_{\mathrm{m} 0}$ $=30 \mathrm{~km}, \alpha_{0}=0.7$ cases, and the $3 \mathrm{~km}$ (c) bubble, and (d) $\mathrm{R}_{\mathrm{m} 0}=40 \mathrm{~km}, \alpha_{0}=0.5$ storms. Superimposed are vectors representing storm motion (C), and the $\mathrm{HA}$ and $\mathrm{DH}^{*}$ contributions to motion identified in the PV analysis (see text). For (d), the $\mathrm{DH}^{*}$ vector has essentially zero length.

model had difficulty propagating forward structural information supplied with the initialization.

The origin of this homogenization is currently unclear, but the results suggest that powerful forces are at work, possibly external, internal, natural and/or numerical. Even in a simplified setting such as imposed here, TC shape and size selection may reflect vortex dynamics or environment factors such as humidity, vertical wind shear and sea-surface temperature. Alternatively, the mature structure may more greatly reflect the internal factors of model resolution or physics, including microphysics, convective and radiation parameterizations, boundary layer and surface schemes, and subgrid-scale turbulence formulations. But the important implication is that initial storm structures, supplied through data assimilation or bogussing, may not be able to persist.

The bubble-initiated runs provide important insight regarding the homogenization process precisely because no specific wind structure was imposed on these simulations at the outset. It is notable that, while it took time, the bubble storms evolved near-core and far field wind profiles bearing substantial resemblance to those finally presented by their bogussed counterparts. If the resulting outer wind profiles are not optimal or even reasonable, this indicates the presence of important model deficiencies, very likely involving the physical parameterizations, that need to be identified and rectified owing to their controlling influence on track forecasts.

Naturally, TC track depends on more than just the beta drift. Convective asymmetries have been shown yet again to be very relevant, making an important difference in forward motion. This points to a remarkable contrast between the bogus and bubble TCs that defied the general trend towards uniformity. For unappreciated reasons, the naturally bred and artificially imposed TCs developed very different vertical shears. This has apparently led to distinctly different 
asymmetric heating patterns that significantly modulated translation via potential vorticity generation.

The results of this study argue for improvements in initialization - from data assimilation or ensemble forecasting techniques that will help further improve position, and possibly, intensity, forecasts and quantify uncertainty - but also a greater recognition of the possibly controlling influence of model physics. Further research with a greater emphasis on validating symmetric and asymmetric storm structures is clearly needed.

Acknowledgements The study was supported by National Science Foundation grant ATM-0554765 with computing support from the Aerospace Corporation.

\section{REFERENCES}

Anthes, R. A., 1982: Tropical Cyclones: Their Evolution Structure and Effects. Meteorological Monographs, 41, American Meteorological Society, 298 pp.

Bender, M. A., 1997: The effect of relative flow on the asymmetric structure in the interior of hurricanes. $J$. Atmos. Sci., 54, 703-724, doi: 10.1175/1520-0469(19 97)054<0703:TEORFO >2.0.CO;2. [Link]

Bender, M. A., R. J. Ross, R. E. Tuleya, and Y. Kurihara, 1993: Improvements in tropical cyclone track and intensity forecasts using the GFDL initialization system. Mon. Weather Rev., 121, 2046-2061, doi: 10.1175/152 0-0493(1993)121<2046:IITCTA>2.0.CO;2. [Link]

Carr, L. E. and R. L. Elsberry, 1990: Observational evidence for predictions of tropical cyclone propagation relative to environmental steering. J. Atmos. Sci., 47, 542-546, doi: 10.1175/1520-0469(1990)047<0542:OEFPOT>2. $0 . \mathrm{CO} ; 2$. [Link]

Chan, J. C. L., 2010: Movement of tropical cyclones. In: Chan, J. C. L. and J. D. Kepert (Eds.), Global Perspectives on Tropical Cyclones: From Science to Mitigation, World Scientific Publishing Company, 133-148.

Chan, J. C. L. and W. M. Gray, 1982: Tropical cyclone movement and surrounding flow relationship. Mon. Weather Rev., 110, 1354-1374, doi: 10.1175/1520-04 93(1982) $110<1354:$ TCMASF $>2.0$.CO;2. [Link]

Chan, J. C. L. and R. T. Williams, 1987: Analytical and numerical studies of the beta-effect in tropical cyclone motion. Part I: Zero mean flow. J. Atmos. Sci., 44, 1257 -1265, doi: 10.1175/1520-0469(1987)044<1257:AAN SOT>2.0.CO;2. [Link]

Cocks, S. B. and W. M. Gray, 2002: Variability of the outer wind profiles of western north pacific typhoons: Classifications and techniques for analysis and forecasting. Mon. Weather Rev., 130, 1989-2005, doi: 10.1175/152 0-0493(2002)130<1989:VOTOWP>2.0.CO;2. [Link]

Corbosiero, K. L. and J. Molinari, 2002: The effects of vertical wind shear on the distribution of convection in tropical cyclones. Mon. Weather Rev., 130, 2110-2123, doi: 10.1175/1520-0493(2002)130<2110:TEOVWS> 2.0.CO;2. [Link]

Corbosiero, K. L. and J. Molinari, 2003: The relationship between storm motion, vertical wind shear, and convective asymmetries in tropical cyclones. J. Atmos. Sci., 60, 366-376, doi: 10.1175/1520-0469(2003)060 $<0366$ :TRBSMV>2.0.CO;2. [Link]

Davis, C., W. Wang, S. S. Chen, Y. Chen, K. Corbosiero, M. DeMaria, J. Dudhia, G. Holland, J. Klemp, J. Michalakes, H. Reeves, R. Rotunno, C. Snyder, and Q. Xiao, 2008: Prediction of landfalling hurricanes with the Advanced Hurricane WRF Model. Mon. Weather Rev., 136, 1990-2005, doi: 10.1175/2007MWR2085.1. [Link]

DeMaria, M., 1985: Tropical cyclone motion in a nondivergent barotropic model. Mon. Weather Rev., 113, 11991210, doi: 10.1175/1520-0493(1985)113<1199:TCMI AN>2.0.CO;2. [Link]

DeMaria, M., 1987: Tropical cyclone track prediction with a barotropic spectral model. Mon. Weather Rev., 115, 2346-2357, doi: 10.1175/1520-0493(1987)115<2346: TCTPWA $>2.0 . C O ; 2$. [Link]

Depperman, C. E., 1947: Notes on the origin and structure of Philippine typhoons. Bull. Amer. Meteorol. Soc., 28, 399-404.

Elsberry, R. L., 1995: Recent advancements in dynamical tropical cyclone track predictions. Meteorol. Atmos. Phys., 56, 81-99, doi: 10.1007/BF01022522. [Link]

Emanuel, K. A., 1986: An air-sea interaction theory for tropical cyclones. Part I: Steady-state maintenance. $J$. Atmos. Sci., 43, 585-605, doi: 10.1175/1520-0469(19 86)043<0585:AASITF>2.0.CO;2. [Link]

Emanuel, K. A., 2004: Tropical cyclone energetics and structure. In: Fedorovich, E., R. Rotunno, and B. Stevens (Eds.), Atmospheric Turbulence and Mesoscale Meteorology, Cambridge University Press, 165-191.

Fiorino, M. and R. L. Elsberry, 1989a: Some aspects of vortex structure related to tropical cyclone motion. $J$. Atmos. Sci., 46, 975-990, doi: 10.1175/1520-0469(19 89)046<0975:SAOVSR > 2.0.CO;2. [Link]

Fiorino, M. and R. L. Elsberry, 1989b: Contributions to tropical cyclone motion by small, medium and large scales in the initial vortex. Mon. Weather Rev., 117, 721-727, doi: 10.1175/1520-0493(1989)117<0721:CT $\mathrm{TCMB}>2.0 . \mathrm{CO} ; 2$. [Link]

Fovell, R. G. and H. Su, 2007: Impact of cloud microphysics on hurricane track forecasts. Geophys. Res. Lett., 34, L24810, doi: 10.1029/2007GL031723. [Link]

Fovell, R. G. and D. J. Boucher, 2009: Effect of cloud processes on hurricane tracks: Results from operational forecasts. $13^{\text {th }}$ Conf. on Mesoscale Processes, American Meteorological Society.

Fovell, R. G., K. L. Corbosiero, and H. C. Kuo, 2009: Cloud 
microphysics impact on hurricane track as revealed in idealized experiments. J. Atmos. Sci., 66, 1764-1778, doi: 10.1175/2008JAS2874.1. [Link]

Fovell, R. G., K. L. Corbosiero, A. Seifert, and K. N. Liou, 2010: Impact of cloud-radiative processes on hurricane track. Geophys. Res. Lett., 37, L07808, doi: 10.1029/ 2010GL042691. [Link]

Frank, W. M. and E. A. Ritchie, 1999: Effects of environmental flow upon tropical cyclone structure. Mon. Weather Rev., 127, 2044-2061, doi: 10.1175/1520-04 93(1999) 127<2044:EOEFUT>2.0.CO;2. [Link]

Frank, W. M. and E. A. Ritchie, 2001: Effects of vertical wind shear on the intensity and structure of numerically simulated hurricanes. Mon. Weather Rev., 129, 2249-2269, doi: 10.1175/1520-0493(2001)129<2249: EOVWSO $>2.0 . C O ; 2$. [Link]

Franklin, J. L., S. E. Feuer, J. Kaplan, and S. D. Aberson, 1996: Tropical cyclone motion and surrounding flow relationships: Searching for beta gyres in Omega dropwindsonde datasets. Mon. Weather Rev., 124, 64-84, doi: 10.1175/1520-0493(1996)124<0064:TCMASF> 2.0.CO;2. [Link]

Fujita, T., 1952: Pressure distribution within a typhoon. Geophys. Mag., 23, 437-451.

Goerss, J. S., 2000: Tropical cyclone track forecasts using an ensemble of dynamical models. Mon. Weather Rev., 128, 1187-1193, doi: 10.1175/1520-0493(2000)128<1 187:TCTFUA $>2.0 . C O ; 2$. [Link]

Goerss, J. S. and R. A. Jeffries, 1994: Assimilation of synthetic tropical cyclone observations into the Navy Operational Global Atmospheric Prediction System. Weather Forecast., 9, 557-576, doi: 10.1175/1520-043 4(1994)009<0557:AOSTCO>2.0.CO;2. [Link]

Heming J. and J. Goerss 2010: Track and structure forecasts of tropical cyclones. In: Chan, J. C. and J. D. Kepert (Eds.), Global Perspectives on Tropical Cyclones: From Science to Mitigation, World Scientific Publishing Company, 287-323.

Hill, K. A. and G. M. Lackmann, 2009a: Analysis of idealized tropical cyclone simulations using the Weather Research and Forecasting Model: Sensitivity to turbulence parameterization and grid spacing. Mon. Weather Rev., 137, 745-765, doi: 10.1175/2008MWR2220.1. [Link]

Hill,K.A. and G. M.Lackmann, 2009b: Influence of environmental humidity on tropical cyclone size.Mon. Weather Rev., 137, 3294-3315, doi: 10.1175/2009MWR2679.1. [Link]

Holland, G. J., 1980: An analytic model of the wind and pressure profiles in hurricanes. Mon. Weather Rev., 108, 1212-1218, doi: 10.1175/1520-0493(1980)108<1212: AAMOTW $>2.0 . C O ; 2$. [Link]

Holland, G. J. 1983: Tropical cyclone motion: Environmental interaction plus a beta effect. J.Atmos. Sci., 40, 328-
342, doi: 10.1175/1520-0469(1983)040<0328:TCMEI P>2.0.CO;2. [Link]

Holland, G. J., 1984: Tropical cyclone motion. A comparison of theory and observation. J. Atmos. Sci., 41, 6875, doi: 10.1175/1520-0469(1984)041<0068:TCMAC $\mathrm{O}>2.0 . \mathrm{CO} ; 2$. [Link]

Holland, G. J. 1985: Mature structure and structure change. In: Chan, J. C. and J. D. Kepert (Eds.), Global Perspectives on Tropical Cyclones: From Science to Mitigation, World Scientific Publishing Company, 13-52.

Holland, G. J., J. I. Belanger, and A. Fritz, 2010: A revised model for radial profiles of hurricane winds. Mon. Weather Rev., 138, 4393-4401, doi: 10.1175/2010MW R3317.1. [Link]

Hsu, S. A. and Z. Yan, 1998: A note on the radius of maximum wind for hurricanes. J. Coast. Res., 14, 667-668.

Hughes, L. A., 1952: On the low level wind structure of typhoons. Tech. Note No. 2, Japan Typhoon Research Laboratory, $45 \mathrm{pp}$.

Jordan, C. L., 1958: Mean soundings for the West Indies area. J. Meteorol., 15, 91-97, doi: 10.1175/1520-0469 (1958)015<0091:MSFTWI>2.0.CO;2. [Link]

Jorgensen, D. F., 1984: Mesoscale and convective-scale characteristics of mature hurricanes. Part I: General observations by research aircraft. J. Atmos. Sci., 41, 12681286, doi: 10.1175/1520-0469(1984)041<1268:MACS $\mathrm{CO}>2.0 . \mathrm{CO} ; 2$. [Link]

Kain, J. S., 2004: The Kain-Fritsch convective parameterization: An update. J. Appl. Meteorol., 43, 170-181, doi: 10.1175/1520-0450(2004)043<0170:TKCPAU>2.0. CO;2. [Link]

Kepert D. J. 2010: Tropical Cyclone Structure and Dynamics. In: Chan, J. C. and L. D. Kepert (Eds.), Global Perspectives on Tropical Cyclones: From Science to Mitigation, World Scientific Publishing Company, 3-54.

Kimball, S. K., 2006: A modeling study of hurricane landfall in a dry environment. Mon. Weather Rev., 134, 19011918, doi: 10.1175/MWR3155.1. [Link]

Kimball, S. K. and M. S. Mulekar, 2004: A 15-year climatology of North Atlantic tropical cyclones. Part I: Size parameters. J. Climate, 17, 3555-3575, doi: 10.1175/15 20-0442(2004)017<3555:AYCONA>2.0.CO;2. [Link]

Krishnamurti, T. N, R. Correa-Torres, G. Rohaly, D. Oosterhof, and N. Surgi, 1997: Physical initialization and hurricane ensemble forecasts. Weather Forecast., 12, 503-514,doi: 10.1175/1520-0434(1997)012<0503:PIA HEF $>2.0 . C O ; 2$. [Link]

Kurihara, Y., M. A. Bender, R. E. Tuleya, and R. J. Ross, 1990: Prediction experiments of Hurricane Gloria (1985) using a multiply nested movable mesh model. Mon. Weather Rev., 118, 2185-2198, doi: 10.1175/152 0-0493(1990)118<2185:PEOHGU>2.0.CO;2. [Link]

Leroux, M. D., 2010: Prediction and diagnosis of the motion and rapid intensification of Typhoon Sinlaku dur- 
ing TCS08 (Tropical Cyclone Structure Experiment, 2008). Preprints, $29^{\text {th }}$ Conference on Hurricanes and Tropical Meteorology, American Meteorological Society.

Leslie, L. M. and G. J. Holland, 1995: On the bogussing of tropical cyclones in numerical models: A comparison of vortex profiles. Meteorol. Atmos. Phys., 56, 101-110, doi: 10.1007/BF01022523. [Link]

Leslie, L. M., J. F. LeMarshall, R. P. Morison, C. Spinoso, R. J. Purser, N. Pescod, and R. Seecamp, 1998: Improved hurricane track forecasting from the continuous assimilation of high quality satellite wind data. Mon. Weather Rev., 126, 1248-1258, doi: 10.1175/1520-049 3(1998)126<1248:IHTFFT>2.0.CO;2. [Link]

Lin, Y. L., R. D. Farley, and H. D. Orville, 1983: Bulk parameterization of the snow field in a cloud model. $J$. Climate Appl. Meteorol., 22, 1065-1092, doi: 10.11 75/1520-0450(1983)022<1065:BPOTSF>2.0.CO;2. [Link]

Liu, K. S. and J. C. Chan, 2002: Synoptic flow patterns associated with small and large tropical cyclones over the western North Pacific. Mon. Weather Rev., 130, 21342142, doi: 10.1175/1520-0493(2002)130<2134:SFPA WS $>2.0 . \mathrm{CO} ; 2$. [Link]

Lord, S., 1991: A bogussing system for vortex circulations in the National Meteorological Center global forecast model. Preprints, $19^{\text {th }}$ Conf. on Hurricanes and Tropical Meteorology, Miami, FL, Amer. Meteor. Soc., 328330 .

Mallen, K. J., M. T. Montgomery, and B. Wang, 2005: Reexamining the near-core radial structure of the tropical cyclone primary circulation: Implications for vortex resiliency. J. Atmos. Sci., 62, 408-425, doi: 10.1175/JAS -3377.1. [Link]

Merrill, R. T., 1984: A comparison of large and small tropical cyclones. Mon. Weather Rev., 112, 1408-1418, doi: 10.1175/1520-0493(1984)112<1408:ACOLAS >2.0.C $\mathrm{O} ; 2$. [Link]

Miyoshi, T., T. Komori, H. Yonehara, R. Sakai, and M. Yamaguchi, 2010: Impact of resolution degradation of the initial condition on typhoon track forecasts. Weather Forecast., 25, 1568-1573, doi: 10.1175/2010WAF222 2392.1. [Link]

Qiu, X., Z. M. Tan, and Q. Xiao, 2010: The roles of vortex Rossby waves in hurricane secondary eyewall formation. Mon. Weather Rev., 138, 2092-2109, doi: 10.11 75/2010MWR3161.1. [Link]

Rappaport, E. N., J. L. Franklin, L. A. Avila, S. R. Baig, J. L. Beven II, E. S. Blake, C. A. Burr, J. G. Jiing, C. A. Juckins, R. D. Knabb, C. W. Landsea, M. Mainelli, M. Mayfield, C. J. McAdie, R. J. Pasch, C. Sisko, S. R. Stewart, and A. N. Tribble 2009: Advances and challenges at the National Hurricane Center. Weather Forecast., 24, 395-419, doi: 10.1175/2008WAF2222128.1.
[Link]

Reasor, P. D., M. T. Montgomery, and, L. D. Grasso, 2004: A new look at the problem of tropical cyclones in vertical shear flow: Vortex resiliency. J. Atmos. Sci., 61, 3-22, doi: 10.1175/1520-0469(2004)061<0003:ANLA $\mathrm{TP}>2.0 . \mathrm{CO} ; 2$. [Link]

Riehl, H., 1954: Tropical Meteorology, McGraw-Hill New York, 392 pp.

Riehl, H., 1963: Some relations between wind and thermal structure of steady state hurricanes. J. Atmos. Sci., 20, 276-287, doi: 10.1175/1520-0469(1963)020<0276:SR BWAT>2.0.CO;2. [Link]

Rogers, R., S. Aberson, M. Black, P. Black, J. Cione, P. Dodge, J. Gamache, J. Kaplan, M. Powell, J. Dunion, E. Uhlhorn, N. Shay, and N. Surgi, 2006: The intensity forecasting experiment: A NOAA multiyear field program for improving tropical cyclone intensity forecasts. Bull. Amer. Meteorol. Soc., 87, 1523-1537, doi: 10.1175/BAMS-87-11-1523. [Link]

Rotunno, R. and K. A. Emanuel, 1987: An air-sea interaction theory for tropical cyclones. Part II: Evolutionary study using a nonhydrostatic axisymmetric numerical model. J. Atmos. Sci., 44, 542-561, doi: 10.1175/15200469(1987)044<0542:AAITFT>2.0.CO;2. [Link]

Schloemer, R. W., 1954: Analysis and synthesis of hurricane wind patterns over Lake Okeechobee. Florida. Hydrometeorological Report No. 31, 49 pp.

Shapiro, L. J. and H. E. Willoughby, 1982: The response of balanced hurricanes to local sources of heat and momentum. J. Atmos. Sci., 39, 378-394, doi: 10.1175/152 0-0469(1982)039<0378:TROBHT>2.0.CO;2. [Link]

Shea, D. J. and W. M. Gray, 1973: The hurricane's inner core region. I. Symmetric and asymmetric structure. $J$. Atmos. Sci., 30, 1544-1564, doi: 10.1175/1520-0469 (1973)030<1544:THICRI >2.0.CO;2. [Link]

Smith, R. B., 1993: A hurricane beta-drift law. J. Atmos. Sci., 50, 3213-3220, doi: 10.1175/1520-0469(1993)05 $0<3213$ :AHBDL $>2.0 . \mathrm{CO} ; 2$. [Link]

Smith, R. K., W. Ulrich, and G. Dietachmayer, 1990: A numerical study of tropical cyclone motion using a barotropic model. I: The role of vortex asymmetries. $Q$. $J$. R. Meteorol. Soc., 116, 337-362, doi: 10.1002/qj.4971 1649206. [Link]

Srinivas, C. V., R. Venkatesan, D. V. Bhaskar Rao, and D. Hari Prasad , 2007: Numerical simulation of Andhra severe cyclone (2003): Model sensitivity to the boundary layer and convection parameterization. Pure Appl. Geophys., 164, 1465-1487, doi: 10.1007/s00024-0070228-1. [Link]

Torn, R. D., 2010: Performance of a mesoscale ensemble Kalman filter (EnKF) during the NOAA High-Resolution Hurricane test. Mon. Weather Rev., 138, 43754392, doi: 10.1175/2010MWR3361.1. [Link]

Vickery, P. J. and D. Wadhera, 2008: Statistical models of 
Holland pressure profile parameter and radius to maximum winds of hurricanes from flight-level pressure and $\mathrm{H}^{*}$ wind data. J. Appl. Meteorol. Climatol., 47, 2497-2517, doi: 10.1175/2008JAMC1837.1. [Link]

Wang, Y., 2009: How do outer spiral rainbands affect tropical cyclone structure and intensity? J. Atmos. Sci., 66, 1250-1273, doi: 10.1175/2008JAS2737.1. [Link]

Weatherford, C. L. and W. M. Gray, 1988a: Typhoon structure as revealed by aircraft reconnaissance. Part I: Data analysis and climatology. Mon. Weather Rev., 116, 1032-1043, doi: 10.1175/1520-0493(1988)116<1 032:TSARBA>2.0.CO;2. [Link]

Weatherford, C. L. and W. M. Gray, 1988b: Typhoon structure as revealed by aircraft reconnaissance. Part II: Structural variability. Mon. Weather Rev., 116, 10441056, doi: 10.1175/1520-0493(1988)116<1044:TSAR $\mathrm{BA}>2.0 . \mathrm{CO} ; 2$. [Link]

Willoughby, H. E., 1990: Temporal changes of the primary circulation in tropical cyclones. J. Atmos. Sci., 47, 242264, doi: 10.1175/1520-0469(1990)047<0242:TCOTP C>2.0.CO;2. [Link]

Willoughby, H. E. and M. E. Rahn, 2004: Parametric representation of the primary hurricane vortex. Part I: Observations and evaluation of the Holland (1980) model. Mon. Weather Rev., 132, 3033- 3048, doi: 10.1175/M WR2831.1. [Link]

Willoughby, H. E., R. W. R. Darling, and M. E. Rahn, 2006:
Parametric representation of the primary hurricane vortex. Part II: A new family of sectionally continuous profiles. Mon. Weather Rev., 134, 1102-1120, doi: 10. 1175/MWR3106.1. [Link]

Wong,K. Y., 2008: Effects of microphysics schemes and initial environmental relative humidity on hurricane track and intensity in idealized simulations. Master Thesis, Department of Atmospheric and Oceanic Sciences, University of California, Los Angeles, USA, 100 pp.

Wu, L. and B. Wang, 2000: A potential vorticity tendency diagnostic approach for tropical cyclone motion. Mon. Weather Rev., 128, 1899-1911, doi: 10.1175/1520-04 93(2000)128<1899:APVTDA>2.0.CO;2. [Link]

Wu, L. and B. Wang, 2001: Effects of convective heating on movement and vertical coupling of tropical cyclones: A numerical study. J. Atmos. Sci., 58, 3639-3649, doi: 10.1175/1520-0469(2001)058<3639:EOCHOM>2.0. $\mathrm{CO} ; 2$. [Link $]$

$\mathrm{Xu}$, J. and Y. Wang, 2010: Sensitivity of the simulated tropical cyclone inner-core size to the initial vortex size. Mon. Weather Rev., 138, 4135-4157, doi: 10.1175/201 OMWR3335.1. [Link]

Zou, X. and Q. Xiao, 2000: Studies on the initialization and simulation of a mature hurricane using a variational bogus data assimilation scheme. J. Atmos. Sci., 57, 836-860, doi: 10.1175/1520-0469(2000)057<0836:SO TIAS $>2.0 . \mathrm{CO} ; 2$. [Link] 